\title{
EL DEBATE SOBRE LA FILOSOFÍA EN LA RUSIA CONTEMPORÁNEA
}

\author{
Grupo de Investigación ORIENTE-OCCIDENTE \\ Departamento de Lógica Historia y Filosofla de la Ciencia. UNED
}

Resumen: Los autores hacen una presentación general, forzosamente esquemática, de los debates que suscita en Rusia la filosofia como núcleo de los problemas de nuestra cultura: su naturaleza, su papel y su status académico.

Abstract: The Authors do a general and inevitably schematic presentation of discussions that the Philosophy make to raise in the Russian world as core of cultural problems: its essence, its role and its Academic status.

Facetas de un cambio de rumbo

Una de las características del desarrollo intelectual de la nueva Rusia, después del largo período de su existencia en los marcos de la hoy desaparecida Unión Soviética, se puede considerar la desaparición del papel hegemónico de la ideología seudo marxista y la liberación definitiva de la filosofia de las imposiciones y arbitrariedades de la variante de la filosofia dogmática impuesta por el régimen -el materialismo dialéctico e bistórico-. Esta liberación que ha sido, ante todo, el resultado de un largo y difficil proceso que ha tenido lugar en la segunda mitad del siglo XX, se inicia dentro de la propia filosofia soviética, superando las barreras ideológicas y políticas del pensamiento filosófico oficial. Proceso que hoy día ha sido lamentablemente olvidado por aquellos que al intentar impulsar el desarrollo económico y social del País por el incierto y erróneo camino de las reformas neoliberales han creído que con el retorno mecánico a los modelos político-sociales de la cultura occidental y el rechazo frontal y total de la experiencia de la industrialización useudo-socialista» 0 , simplemente, 
no capitalista se abrirían de par en par las puertas por las que en Rusia penetraría la cultura Occidental, y con ella llegaría el pensamiento filosófico contemporáneo que desplazaría de una vez para siempre la filosofía marxista ideológica y dogmática, en los marcos de la cual no podía haber surgido nada nuevo, debido a que durante el período soviético la creatividad filosófica era imposible y ésta estaba sumergida en un abismo del cual sería muy difícil salir.

La realidad ha mostrado que esta opinión era una grave equivocación que no sólo falseaba la situación rusa y sobrevaloraba extremadamente los logros y el papel de la filosofía occidental europea y americana. No obstante, es necesario señalar que tales planteamientos radicales han sido duramente criticados por su evidente y profundo desconocimiento de la historia, la situación real y los profundos cambios acontecidos en las últimas décadas del siglo XX en las que en la filosofía (aún soviética) ya existían una gran diversidad de enfoques e ideas, que a pesar de desarrollarse y presentarse como versiones del enfoque marxista, en realidad rebasaban ampliamente los marcos de esta teoría, pero también, y esto es posiblemente lo más importante, habían conseguido crear poco a poco "focos de resistencia" o sectores relativamente libres de las imposiciones e intromisiones del dogmatismo filosófico oficial, por ejemplo: en la historia de la filosofía, en la filosofía de la ciencia, en la lógica etc.

Creo que un sólo ejemplo sería suficiente para explicar la esencia y el mecanismo de este complejo fenómeno. El conocido filósofo ruso (soviético en su tiempo) A. A. Zinoviev nos ofrece un somero relato de los motivos y las circunstancias que le impulsaron ya entonces al campo de las investigaciones lógicas. Según sus palabras en la etapa inicial de su trabajo como filósofo había pensado dedicarse al estudio de la sociedad, pero muy pronto descubrió que tanto el marxismo como el no marxismo no le ofrecían ni una teoría ni un método riguroso para su estudio. La búsqueda de estos le llevó al campo de la lógica y añade:

«Por cierto yo no tenía otra elección. Las circunstancias de mi vida así lo decidieron y la elección se impuso independientemente de mis intenciones. Ocurrió que a fin de cuentas fui impulsado por mis superiores y colegas hacia la lógica, debido a que yo no pertenecía al partido y mantenía una actitud crítica hacia el marxismo y la lógica se consideraba ideológicamente neutral» ${ }^{1}$.

1 ZiNoviev, A. A. «Tógica complejan, en Voprosy Filosofii. n. ${ }^{\circ}$ 1, 2003. pp. 29-30. 
En una palabra, en estos momentos ya casi nadie pone en duda que en la Rusia actual el desarrollo de la filosofía ha seguido su propio camino y ha realizado los cambios necesarios utilizando sus propias tradiciones y experiencia. El académico V.S. Stiopin en su libro La época de cambios y los escenarios del futuro en el que nos describe los caminos recorridos por la filosofía rusa desde su separación de la Unión Soviética, y nos habla de la compleja situación actual, además de reconocer el hecho "de la existencia de no pocos servidores de la filosofia ideologizada y predicadores dogmáticos del marxismo", muestra también detalladamente que ya a partir de mediados de los años 60 la resistencia al marxismo oficial se desarrolla ampliamente por diferentes caminos que van desde el estudio profundo de las obras de los clásicos" (tergiversadas o ignoradas por la ideología oficial) hasta la asimilación de aquellos aspectos de la filosofía occidental que representaban las nuevas tendencias en el desarrollo de esta disciplina. Estas líneas de desarrollo cobran fuerza en los años 70-80 y durante este período se publican interesantes trabajos que rompen los moldes del dogmatismo oficial Los nombres de sus autores y sus ideas son bien conocidos y no sólo por la comunidad científica y filosófica. El resultado de este trabajo es el hecho de que al hablar de la filosofía soviética de estos años ya no se puede afirmar que en ella existía un paradigma marxista común. Por otra parte, es también una realidad palpable que ya entonces los contactos con los filósofos de otros países eran cada vez más numerosos, intensos y fructíferos, así como la participación soviética en los eventos internacionales.

Stiopin al referirse a la situación existente en este período escribe, que fue entonces cuando

«se inició la asimilación intensiva de los resultados obtenidos por la filosofía mundial en sus corrientes no marxistas. La polémica con estas estimuló la aparición de diversas concepciones que se presentaban aparentemente como variantes del marxismo, pero que se diferenciaban considerablemente confrecuencia de sus variantes clásicas" ${ }^{2}$.

En una palabra, cuando a mediados de los 80 en la Unión Soviética se inicia el proceso que conocemos como «Perestroika» la filosofía y los filósofos del país ya estaban preparados para romper definitiva y radicalmente con el dogmatismo

2 CTIOPIN, V. S. La época de cambios y los escenarios delfuturo. M. 1996. p. 93. 
del pensamiento filosófico oficial de la etapa precedente. De este modo, es necesario reconocer que ya entonces, en los marcos del "socialismo real" y en oposición a la ideología imperante, la propia filosofia habían creado las premisas y las condiciones de un cambio radical del pensamiento y la actividad filosófica que, como acertadamente destaca Stiopin en el libro citado, no está pasando ahora por una situación de crisis, ni se encuentra en ese profundo abismo en el que como se pronosticaba permanecería durante largo tiempo. Según Stiopin

"las habladurías sobre la profundización de la crisis de nuestra filosofía son, dicho con cierta suavidad, poco responsables. No son otra cosa que la continuación de los viejos clichés ideológicos. Muchos de aquellos que antes hablaban de la única filosofía correcta del materialismo dialéctico y de la crisis del pensamiento filosófico occidental (apropiándose con frecuencias sin citarlo de sus ideas y hasta de sus textos) son los que hoy día proclaman el estado de crisis de la filosofía en Rusia" ${ }^{3}$.

La falsedad denunciada en esta afirmación se confirma por una serie de hechos reales entre los que sólo queremos mencionar dos que se pueden observar a primera vista: el gran interés de la población por la literatura filosófica (las nuevas ediciones desaparecen de la estantería de las librerías con gran rapidez) y el aumento de la "producción" de obras filosóficas. De esto último sólo citaremos un ejemplo: en el año 2001 los investigadores del Instituto de Filosofía de la ACR. editaron 108 libros $^{4}$, tantos como editaba en la etapa soviética este mismo Instituto con más investigadores en 10 años (en 1976-10, en 1977-8, en 1978-13, etc.) $)^{5}$.

Es cierto, que en la difícil situación actual de crisis generalizada de los valores fundamentales de la civilización tecnogénica los problemas sin resolver son cada día más complejos y numerosos, se acumulan ante el pensamiento filosófico tanto oriental como occidental que se siente abrumado no sólo por la falta de nuevas ideas, sino por el lastre de las ideas conservadoras heredadas de las viejas tradiciones culturales. En este sentido parece evidente, que esta falta de

3 Op. cit. p. 95.

4 "Libros editados por los investigadores del Instituto de Filosofía de la ACR en el año 2001 ", en Voprosy Filosofii, n. ${ }^{\circ}$ 7, 2002 pp. 188-190.

5 Trabajos cientificos del Instituto de Filosofía (Lista bibliográfica de los años 1929-1978) Moscú, 1979, pp. 148-163. 
criterios es un mal que afecta en general a toda la filosofía. En lo que se refiere a la filosofía rusa actual tenemos la impresión de que en ella la toma de conciencia de la gravedad de esta situación y de la necesidad imperiosa de soluciones urgentes es ya una realidad palpable. Una toma de conciencia que se ha visto incentivada y estimulada por las incidencias de un pasado aún presente, del cual acaba de emerger victoriosa en una lucha feroz contra el dogmatismo, el inmovilismo y las trabas ideológicas del poder establecido y de la cual ha asimilado una lección - la filosofia nunca puede renunciar a su función de critica constructiva para convertirse en el respaldo ideológico del poder fáctico-.

Por lo tanto, al hablar del pensamiento filosófico de la Rusia actual no nos debe sorprender que después de ganada una batalla en la que ha recuperado su identidad y capacidad creativa, se haya visto obligado a continuar esta labor crítica hasta sus últimas consecuencias y formular las conclusiones pertinentes que permitan poner un punto final a una situación que no debe repetirse en el futuro. Una labor que ha requerido no sólo el análisis objetivo y la crítica constructiva de su pasado histórico, sino también el decisivo rechazo de los múltiples mitos y falsedades que se han vertido y divulgado sobre éste. Pero la crítica de por sí hubiera sido estéril si no se hubiera visto acompañada por la constante búsqueda de aquellas nueva ideas y valores que el pensamiento filosófico está "obligado a encontrar" para poder cumplir en el futuro inmediato ese papel innovador que, por definición, debe realizar la filosofía.

En la exposición de nuestro tema no nos hemos propuesto ni ofrecer un panorama general del desarrollo de la filosofía en Rusia durante los últimos años, ni realizar un análisis objetivo de los múltiples problemas e ideas que lo caracterizan. Nos hemos limitado a presentar algunas piezas (en el título las hemos definido como facetas) de un amplio mosaico que reflejan algunos de los momentos claves de la dirección y la esencia de los cambios: la superación del dogmatismo, la elaboración de una nueva enciclopedia filosófica, el cambio de programa de filosofia para los aspirantes a doctores en las diferentes ciencias, y la discusión pública sobre el objeto y la necesidad de la filosofia.

\section{El antidogmatismo}

Entre los muchos autores que hoy día han aportado elementos de valor en el análisis crítico, objetivo y constructivo de la filosofia soviética de la etapa precedente consideramos que el académico T. I. Oizerman es una de las figuras 
más cualificadas y representativas. En la etapa soviética ha sido autor de decenas de libros y cientos de artículos sobre diferentes problemas de la filosofía y su historia, editados en Rusia y en otros países ${ }^{6}$. T. I. Oizeman está considerado también uno de los investigadores más serios de la filosofía clásica alemana 7 .

Después de la desintegración de la Unión Soviética T. I. Oizerman realiza una importante labor en el análisis crítico de algunos de los aspectos negativos del marxismo dogmático y la práctica política del "Socialismo real", cuyo resultado se publica en una serie de artículos en la revista Voprosy Filosofii ${ }^{8}$. Todos los temas tratados en los artículos mencionados ofrecen sin duda gran interés y pueden ser, posiblemente, objeto de un estudio especial que ofrezca un panorama integral más amplio de esta crítica constructiva de la etapa precedente que se lleva a cabo desde dentro de la propia filosofía rusa. Pero nosotros, sólo como muestra, nos vamos a limitar a exponer algunas de las cuestiones que se plantean en el último de los citados artículos y en el que se aborda un tema que se ha considerado definitorio en la valoración del marxismo de la época soviética - su dogmatismo y la lucha contra éste uno de los caminos magistrales de la renovación filosófica actual-

El énfasis antidogmático en el pensamiento filosófico en la Rusia post soviética no nos puede sorprender. Los tres cuartos de siglo de "socialismo real" han generado sin duda un clima intelectual alérgico a este mal social. De aquí la enorme importancia de que el estudio "interdisciplinario" de este fenómeno que durante tantos años ha "maltratado al país" no se vea limitado a la búsqueda de paliativos parciales valorativos y moralizantes, sino que se centre en la elaboración de una definitiva vacuna.

6 Entre sus libros más conocidos se pueden citar: La formación de la filosofia del marxismo. $1 .^{2}$ edición rusa M. $1862,3 .^{2}$ M. 1986, (La Habana 1980); Problemas de la ciencia bistórico filosófica. M. 1962 (en castellano está editado en La Habana); Las direcciones fundamentales de la filosofia. M. 1971; El materialismo dialéctico y la historia de la filosofia. M. 1979; Los fundamentos del proceso histórico-filosofico. M. 1983; Lo racional y lo irracional. M. 1983; Critica del racionalismo critico. M. 1988; La concepción cientifico-filosófica del mundo del marxismo. M. 1989.

7 La filosofia de Fichte. M. 1962; La filosofia de Kant. M. 1974; La doctrina histórico-filosófica de Hegel. M. 1982; La teoria del conocimiento de Kant. M. 1991.

8 Entre estos: "Pensamientos y afórismos", en n. ${ }^{\circ} 10,1991$; «Existen las verdades abstractas?", en los n. 2 y 6 1999; "Ensayos de análisis crítico del materialismo dialéctico", en n. ${ }^{\circ} 2,2000$; "Interpretación materialista de la historia: la positivo y lo negativo", $n .^{\circ} 2,2001$; "La concepción marxista del socialismo y el socialismo real", en los n. 2 y 3, 2002; "La dogmatización del marxismo y el dogmatismo interno inherente al marxismon, en $n .^{\circ} 2,2003$. 
$\mathrm{Al}$ abordar en su artículo esta cuestión Oizerman destaca con cierta insistencia la vocación antidogmática personal de C. Marx y F. Engels, citando las múltiples y conocidas manifestaciones de estos autores contra el dogmatismo en general: en la filosofía, en la ciencia y en la política y específicamente su enérgica protesta contra los reiterados intentos de unos $u$ otros de sus seguidores de interpretar y divulgar las ideas «marxistas» con espíritu dogmático. Oizerman recuerda que en su carta a Sombart del 11 de marzo de 1895 Engels le reiteraba que

"la teoría de Marx no es una doctrina, sino un método que no ofrece dogmas ya preparados, sino puntos de partida para la posterior investigación ${ }^{9}$.

En otra de sus cartas dirigida a Smith (5 de mayo de 1890) dice:

«... la interpretación materialista de la historia tiene ahora muchos amigos para los cuales ésta es tan sólo una excusa para no estudiar la historia. La situación es absolutamente la misma que cuando Marx al hablar de los "marxistas" franceses a fines de los 70 decía: yo sólo se una cosa, que no soy marxista" ${ }^{10}$.

Ante el peligro evidente de que sus ideas se pudieran aceptar, interpretar y aplicar mecánicamente siempre estuvieron alerta ante las posibles desviaciones dogmáticas de sus seguidores repitiendo que su teoría era una teoría del desarrollo y "no un dogma que se debe aprender de memoria y repetir mecánicamente» ${ }^{11}$. Por eso, cuando la aplicación de las ideas marxistas por sus partidarios en el movimiento obrero europeo alcanza un alto nivel de dogmatización Marx y Engels se vieron obligados a pasar de las recomendaciones y declaraciones verbales o epistolares a una exposición teórica sistemática de su credo antidogmático. Oizerman en su artículo recuerda que Engels en el Anti Dühring dedica un capítulo especial (el IX) a la fundamentación gnoseológica de la oposición radical del marxismo a cualquier tipo de dogmatismo y en él que la crítica del dogmatismo en el campo de las ciencias sociales se extiende a las ciencias naturales $y$, especificamente a la física y a la química. Una crítica que

9 C. MarX y F. Engels Obras. T. 39. p. 352.

10 Op. cit. T. 37. p. 370.

11 Op. cit. T. 3 6. p. 504. 
Engels no sólo aplica a sus opositores, sino en mayor medida a sus propios partidarios. Tal es el caso del socialista francés G. Devil que, según Engels, en un trabajo dedicado al Capital de Marx

«adjudicó,en una serie de casos, un significado absoluto a algunos de los planteamientos de Marx que este último sólo había planteado como relativos y que cran correctos sólo en determinadas condiciones y en ciertos límites» ${ }^{12}$.

No obstante y a pesar de esta vocación antidogmática personal de los «clásicos del marxismo", también parece evidente que en la teoría por ellos desarrollada se pueden captar, tanto en su génesis como en su exposición y aplicación en la práctica política, una serie de particularidades internas objetivas que T. Oizerman define en su artículo como el dogmatismo interno del marxismo. Se trata en primer término, de una interpretación sesgada de la procedencia de algunos planteamientos teóricos de la teoría marxista vinculados en su etapa inicial a su convicción de que la teoría del desarrollo social por ellos elaborada tenía, a diferencia del utopismo socialista precedente, un carácter científico y una estructura similar a la de cualquier otra ciencia del siglo XIX. Es decir, se expresaba por medio de un sistema conceptual y unas leyes científicas que reflejaban adecuadamente procesos reales sometidos a determinado tipo de casualidad objetiva. No se daban cuenta de que al construir su teoría no siempre habían sido científicamente rigurosos en la elección de sus premisas iniciales, una actitud que más tarde el propio Engels Engels había criticado en el Anti Dührig refiriéndose a la ciencia en general. Como ejemplo Oizerman cita con cierto detalle el hecho, hoy día bien conocido, de que algunos planteamientos que Marx y Engels habian formulado en la etapa inicial de su trabajo conjunto ${ }^{13}$ y cuyo origen hipotético en aquella etapa era evidente fueron considerados más tarde por ellos mismos como hechos empíricos comprobados por la experiencia y utilizados como tales en la formulación de algunos de los postulados básicos de su futura teoría socialista. Entre estos, según Oizerman; la idea del papel emancipador del "proletariado" y su papel constructivo en la creación de la ideología comunista de la sociedad del futuro. En el Manifiesto Comunista se reitera que

12 MAR, C., ENGELS, F. Obras

13 Primero en la Ideologia Alemana y luego en EI Manifiesto Comunista 
"esta clase constituye la mayorfa de los miembros de la sociedad y de ellos emana la conciencia de la necesidad de una revolución radical, la conciencia comunista” ${ }^{14}$

y se repite una vez más que la realidad histórica confirmaba empíricamente que la crisis general del sistema capitalista ya se había iniciado Como sabemos unos años más tarde en el $1 .^{\circ}$ tomo de El Capital Marx ofrece una interpretación muy distinta de este "hecho objetivo" demostrando científicamente que la mencionada crisis era tan sólo una de las crisis parciales de usuperproducción», después de las cuales se iniciaba un nuevo ciclo de recuperación de la economía capitalista. No obstante 30 años después en el Anti Düring Engels repite de nuevo que la crisis general del modo de producción capitalista era un hecho real y que éste tenía sus días contados.

Es bien conocido que muchas de las ideas y argumentos que Marx y Engels utilizaron en la elaboración inicial de su teoría fueron durante su vida seriamente reformados e incluso rechazados y renovados. Tal es el caso de la posibilidad del paso al socialismo por medios pacíficos. Posibilidad que Engels expone con bastante claridad en su Introducción al Libro de C. Marx «La lucha de clase en Francia de 1848 y 1850" y cuyas conclusiones siempre fueron ignoradas por el marxismo oficial soviético. No obstante tampoco se puede pasar por alto que fueron los propios clásicos del marxismo los que en las múltiples ediciones de sus trabajos iniciales ${ }^{15}$ no consideraron oportuno introducir los correctivos necesarios que exigían sus propias investigaciones posteriores. Sobre los motivos de esta omisión se han hecho múltiples conjeturas y se ha dicho: que no lo hicieron por motivos tácticos, ideológicos e incluso políticos. Sea como sea, parece evidente también, que esta peculiaridad abría una puerta a las interpretaciones dogmáticas de su pensamiento.

El caso del marxismo dogmático soviético es una muestra palpable de que una vez traspasada esta puerta el camino de la manipulación dogmática de la teoría marxista no tenía límites. El ejemplo de V. I. Lenin es el más elocuente. Al hablar de este personaje, cuyo papel fue decisivo en la fórmación de la ideología del "Bolchevismo" -el nombre de pila del marxismo dogmático soviético-, T. Oizerman recuerda que el propio Lenin que se autodefinía a sí mismo

14 MARX, C., ENGels, F. Obras T. p.

15 Tal es el caso del Manifiesto Comunista 
como un "marxista ortodoxo", en realidad "interpretaba los fundamentos del marxismo con cierta ligereza, tratandolos habitualmente en un espiritu voluntaristam ${ }^{16}$. Interpretaciones cuya implantación dogmática constituyeron la columna vertebral del "seudo marxismo soviético" El caso más evidente de tal interpretación, según Oizerman; fue la renuncia de Lenin a aceptar una de las ideas centrales de la teoría marxista, según la cual la necesidad histórica de la revolución socialista estaba vinculada objetivamente al alto nivel de desarrollo de las fuerzas productivas de la sociedad capitalista, la que Lenin sustituía por su convicción de que para iniciar los cambios revolucionarios pronosticados en la teoría marxista la situación revolucionaria de Rusia a principios de siglo era de por sí suficiente. Este planteamiento no marxista que Oizerman define como "una revisión izquierdista del marxismo" generó esa cadena de argumentaciones y conductas concretas que dieron lugar a una interpretación subjetiva de la realidad histórica y cuyas gravísimas consecuencias se manifestaron trágicamente durante todo el período de existencia del «Socialismo real». En realidad se trataba de un "modelo voluntarista" del desarrollo social, cuya esencia había sido expuesta por el propio Lenin en su polémica con el economista Sujanov en estos términos: primero la liquidación de los capitalistas y los terratenientes, luego la industrialización del país con el apoyo del proletariado (en aquel momento el $5 \%$ de la población activa), lo que permitiría crear las bases económicas de la nueva sociedad socialista, la que, en competencia (incluso lucha) con la sociedad capitalista en decadencia, conduciría a la victoria del socialismo a nivel mundial. En este "programa" la revisión del pensamiento marxista se conjugaba con una dogmatización de los planteamientos iniciales del Manifiesto Comunista. Partiendo de esta revisión de la concepción histórica del marxismo la dirección del partido bolchevique fue elaborando «sobre la marcha" una revisión de todo el pensamiento marxista, creando una ideología que, paradójicamente, declara esta revisión como la única posible valoración del marxismo y se implanta dogmáticamente como la ideología oficial de la sociedad soviética. Refiriéndose a esto Oizerman señala que:

"Nosotros estábamos convencidos de que las concepciones que desde nuestra infancia nos inculcaba la potente máquina propagandística del partido, eran en esencia, nuestras propias ideas y concepciones. Este era el

16 Oizerman, T. I. " la dogmatización del marxismo y el dogmatismo interno inherente al marxismo", en Voprosy Filosofii. N. ${ }^{\circ} 2$ 2003. p. 31. 
ambiente espiritual en la URSS, en el cual florecía con ímpetu una dogmatización nunca vista del marxismo" ${ }^{17}$.

Dogmatización que estaba acompañada con la implantación de dos mitos ideológicos demagógicos o, mejor dicho, dos consignas propagandísticas: la necesidad de desarrollar y profundizar constantemente la teoría marxista y la lucha sin cuartel contra todo tipo de desviaciones revisionistas del pensamiento marxista y la "línea del partido".

Como hoy día ya se ha estudiado con cierto rigor y objetividad uno de los elementos más importantes objeto de la revisión bolchevique del marxismo fueron las ideas filosóficas de Marx y Engels. Esta revisión, se caracteriza entre otras cosas por el "analfabetismo filosófico" de sus promotores y el hecho sin precedentes de que los "trabajos" ${ }^{18}$ de dos ignorantes en esta materia (la filosofía) V. I. Lenin y I. V. Stalin fueran declarados y estudiados como grandes obras del pensamiento filosófico marxista (y mundial). Por ejemplo en el breve Diccionario filosófico de 1955 se puede leer que el libro de Lenin Materialismo y empiriocriticismo

"Inicia una nueva época en el desarrollo de la filosofía del materialismo dialéctico... y... es un modelo de desarrollo creativo de la filosofla marxista, un ejemplo de las ideas comunistas en el campo de la teoría» ${ }^{19}$.

Mientras que al hablar del folleto propagandístico de I. Stalin ( $4 .^{\circ}$ cap. de la Historia del Partido) se dice que en

"esta obra se ofrece una exposición integral y sistemática de los fundamentos de la filosofia marxista"... «se resume la experiencia revolucionaria de la época de mayor riqueza en la historia de la humanidad" ${ }^{20}$.

La imposición de las ideas simplistas de estas dos obras, así como las contradicciones y sandeces que se propagaban como decisiones del partido y sus

17 Op. cit. p. 32

18 Nos referimos al libro de V. Lenin Materialismo y empiriocriticismo, editado en 1909 y duramente criticado por los marxistas rusos de su tiempo A. BOGDANOV, L. AKSELROD, Lunacharsky, G. Plejanov.

19 Diccionario Breve de Filosofia. M. 1955. pp. 272 y 275.

20 Op. cit. p. 343. 
líderes, constituyen la médula de las ideas del dogmatismo ideológico que con el nombre de filosofía marxista se intentan implantar como verdades en última instancia y cuya discusión o no aceptación se pagaba, con demasiada frecuencia, con la pena capital. Evidentemente esta ideología tenía muy poco que ver con el pensamiento marxista, un hecho evidente que ya en 1910 había señalado el conocido científico y filósofo ruso A. A. Bogdanov (seudónimo de A. Malinovsky) que después de leer el mencionado libro de Lenin escribía indignado: "Para defender la filosofia de Marx serta útil... conocerla". $Y$ al destacar también el desconocimiento de Lenin de la filosofía en general y su historia, a pesar de que en el libro abundaban las citas y referencias, decía indignado:

Para un marxista esto es más necesario que cualquier otra cosa. No hay nada más anti-histórico y anti-marxista que un cúmulo de citas de diferentes épocas y escuelas, que no estén acompañadas con un serio anślisis social de la ideas citadas». ${ }^{21}$.

Y acompaniaba estas palabras con una valoración demoledora:

"Una apariencia externa de profunda sabiduría - pero en realidad una ignorancia no menos profunda-m. ${ }^{22}$.

En el artículo de Oizerman La crítica del dogmatismo de la filosofía marxista de la época soviética se centra en una conocida frase de Lenin (que durante muchos años había "adornado" como consigna la sala de actos del Instituto de Filosofia) que decía "La teorta de Marx es todopoderosa por que es cierta». Una sentencia cuyo contenido idealista y subjetivista no sólo contradice a la concepción materialista de la historia, sino al sentido común y que se puede considerar de hecho como el slogan por excelencia del dogmatismo filosófico imperante en el país. Esta consigna transformaba las ideas marxistas en aquello que Engels consideraba inaceptable: en una doctrina, que de este modo las colocaba al margen de toda posible crítica, convirtiéndolas en un sistema de dogmas cerrado a la creatividad científica y filosófica, pero que coincidía plenamente con esa actitud subjetivistade Lenin que T. I. Oizerman describe así:

21 A. BOGDANOV "La caída del gran fetichismo (la crisis contemporánea de la ideología). La fe y la ciencia (Sobre el libro de V. Ilin (seudónimo de Lenin) "Materialismo y empiriocriticismo). M. 1910, en Voprosy Filosofii, n. ${ }^{\circ} 12,1991$, p. 84.

22 Op. cit. p. 84. 
"Lenin en su calidad de fundador y líder carismático del partido bolchevique consideraba dañina la libertad de opinión, el pensamiento diferente cuando estos se referían al programa del partido por él establecido, a su estrategia y su táctica, en una palabra a sus propias ideas y a su política, que él consideraba las únicas correctas" 23 .

Otro conocido filosofo ruso, el académico L. N. Mitrojin añade algunos rasgos a la definición crítica del dogmatismo filosófico en general:

"Existe la opinión de que el dogmatismo diviniza los juicios de los clásicos. ¡Que ingenuidad! Lo que sacraliza es su propia primitiva comprensión, para cuya confirmación se adaptan las citas que se consideran adecuadas para ello. El dogmatismo es ante todo el conocimiento preciso de lo que se puede citar y de lo que no se debe" ${ }^{24}$.

Y para poner un punto no final a este tema quisiéramos mencionar algunas consideraciones que T. I. Oizerman nos ofrece para explicar las circunstancias y los motivos que hicieron posible la dogmatización del pensamiento marxista.

"Yo considero que estas causas radican en que el marxismo que surge como una negación de todas las ideologías, de la ideología en general como una conciencia social en principio ajena a la ciencia, no obstante era de por sí una ideología... toda ideología tiende al dogmatismo, pero una ideología que niega su propia naturaleza ideológica se transforma necesariamente en un sistema de dogmas, o símbolos de fe, los que a pesar de sus diferencias con los dogmas religiosos resulta ser un fenómeno espiritual del mismo orden" ${ }^{25}$.

\section{La Nueva Enciclopedia Filosófica}

Uno de los fenómenos más relevantes de la etapa actual del desarrollo de la filosofia en Rusia está vinculado a la publicación de los cuatro tomos de la

23 Olzerman, T. I. Op. cit. p. 32.

24 MitrojIN, L. N. "Las voces del Congreso", en Voprosy Filosofii, n. ${ }^{\circ}$ 2, 1989. p. 65. (Se refiere al XVIII Congreso Filosófico Mundial de 1988).

25 Oizerman, T. 1. Op. cit. p. 41. 
Nueva Enciclopedia Filosofica ${ }^{26}$. Una obra que ha intentado resumir y recoger de cierta manera los múltiples y profundos cambios acontecidos en el campo de la filosofía durante los últimos veinte años.

La evidencia de estos cambios se hacía cada día más evidente cuando por uno u otro motivo se consultaba alguno de los 5 tomos de la última Enciclopedia Filosófica de la época soviética de los años 60 . Una obra que representaba en algunos de sus aspectos una de las etapas iniciales en el proceso de "liberación" del dogmatismo institucional de la filosofia marxista del período estalinista. Una etapa en la que a pesar de que aún no se habían conseguido superar muchos de los clichés ideológicos del estalinismo, como la afirmación de que la filosofía marxista era la cúspide del pensamiento filosófico mundial, no obstante en una serie de artículos ya se salía fuera de los estrechos marcos de pensamiento oficial. La desaparición de la hegemonía del pensamiento filosófico marxista que se inicia en los ańos 80 y tiene como resultado el surgimiento de un nuevo panorama filosófico en el que aparecen nuevas corrientes, nuevas ideas e investigaciones en las más diversas direcciones y temas del pensamiento filosófico. Por lo tanto no nos debe sorprender que la idea de recoger, ordenar y sistematizar todos esos cambios flotase en el ambiente como una necesidad urgente o como ha dicho el redactor principal de esta edición: V. S Stiopin

"Esto motivó que madurara la decisión de la necesidad de crear una "Nueva Enciclopedia Filosófica", que reflejara todo lo que había sido elaborado durante los últimos 20 ańos en nuestro país y en el extranjero" ${ }^{27}$.

Por otra parte, la "explosión” de la creatividad filosófica post soviética y la diversidad y la disparidad de ideas puestas en circulación exigían la elaboración de una literatura de consulta que introdujera a nivel "académico" claridad y "cordura" en la asimilación del amplio panorama de ideas en "circulación", ofreciendo una información verídica de la filosofía y su historia, colaborando en distinguirlas de otras formas de pensamiento y, lo que no era menos importante, ofreciera una exposición sistemática y coherente del sistema de concep-

26 Nueva enciclopedia filosófica. T. $1^{\circ}, 2000,722$ pp; T. $2 .^{\circ}, 2001,636$ pp.; T. $3 .^{\circ}, 2001$, 694 pp.; T. 4. ${ }^{\circ}, 2001,606$ pp. M. "Misl» Jefes del Proyecto V. S. STIOPIN, G. Yu. Serniguin. Presidente del Consejo de redacción V. S. STIOPIN.

27 STIOPIN, V. S. «Intervención en la mesa redonda sobre la Nueva Enciclopedia Filosófica», en Voprosy Filosoffi, n. ${ }^{\circ}$ 1, 2003, p. 4. 
tos y categorías con las que el pensamiento filosófico contemporáneo expresaba sus ideas y teorías. Una consulta que en la etapa actual de profundos cambios en el sistema de enseñanza de la filosofía contribuiría a facilitar el trabajo de alumnos y profesores, no sólo en la asimilación del saber acumulado por esta forma del conocimiento, sino en la toma de conciencia de los problemas y tareas que se plantean ante ésta en la situación actual.

En la Nueva Enciclopedia todo es realmente nuevo: nuevos redactores, nuevos autores, nuevos criterios y enfoques, nuevos métodos... En su elaboración participaron más de 400 autores que renovaron en cada tomo (escribieron de nuevo) no sólo los términos y conceptos de las entradas típicas e imprescindibles de toda enciclopedia filosófica, sino que aumentaron considerablemente su diccionario: 1.932 nuevos términos y nombres, pero también llevaron a cabo la imprescindible labor de excluir aquellos términos y personajes que figuraban en la Enciclopedia de los 60 y cuyo origen ideológico circunstancial era evidente por ejemplo: Dictadura del proletariado, Hegemonia del proletariado, u obras tan lejanas de la temática filosófica como el libro de V. I. Lenin $E l$ imperialismo etapa superior del capitalismo, así como los nombres de muchos políticos de la etapa del "socialismo real» ajenos a la creación filosófica. Entre los nuevos términos y nombres que figuran en la nueva edición ésta se amplía y enriquece con la inclusión de aquellos filósofos que, ignorados por la filosofía soviética, eran y son imprescindibles para comprender el rico legado intelectual y conceptual de importantes culturas y épocas históricas del pasado y del presente.

Evidentemente todas estas y muchas otras novedades de esta Enciclopedia tienen su origen en una interpretación muy distinta del objeto de la filosofia y su papel en el sistema de la cultura de la que se había intentado imponer durante tantos años. En los artículos centrales de esta como "Cultura", "Filosofia de la cultura", "Filosofia de la historia", "Filosofia de la religión", "Conocimiento", "Ciencia" y, naturalmente, "Filosofia», no sólo encontramos un argumentado análisis crítico de la definición de la filosofía que durante todo el período soviético había sido impuesta por el pensamiento seudo marxista dominante, según el cual la filosofía se definía como "la ciencia sobre las leyes más generales del ser, de la sociedad y el pensamiento", sino que al rechazarla por su estrecho carácter cientista se ofrece una nueva definición con la que se intentan superar tanto las contradicciones y limitaciones a que inducía el evidente carácter cientista la citada definición, como las también conocidas deficiencias de otras definiciones parciales de la filosofía tanto del pasado como 
de nuestros días. Esta definición se basa en el hecho de que los fundamentos del pensamiento filosófico se encuentran en el ámbito general de la cultura y no en una u otra de sus manifestaciones concretas. En este contexto la filosofía es ante todo: la autoconciencia de la cultura, una reflexión sobre sus universales, que implica y hace posible una interrelación sui generis entre la filosofía y la cultura en general y en la que la filosofía pone de manifiesto su capacidad de formular (elaborar) los nuevos sentidos de la concepción del mundo de la cultura ${ }^{28}$.

Como acabamos de señalar en la precedente nota, sobre este tema, que constituye el eje central de esta Enciclopedia y que condiciona el contenido y la exposición de todo el sistema de conceptos y términos que la integran, se tratará con cierto detalle más adelante en la traducción que les ofrecemos de las ponencias presentadas en una Mesa redonda en la que los filósofos rusos discutieron estas cuestiones. Discusión que ya antes había tenido lugar durante el proceso de preparación y elaboración de la Nueva Enciclopedia Filosofica. Pero cuya ejecución, llevada a cabo en un breve período (algo más de dos años) exigió además un enorme esfuerzo organizativo y una minuciosa coordinación en la redacción final de todos los textos, que fueron ampliamente discutidos por los especialistas en las diferentes ramas y direcciones del saber filosófico, para lograr, en la mayoría de los casos, la síntesis de posiciones y enfoques a primera vista diferentes. Un ejemplo concreto de cómo se logró esa unidad lo puede, posiblemente, explicar esta frase:

"La unidad no de carácter ideológico sino intelectual en los artículos sobre la filosofía de la ciencia, pertenecientes a diferentes autores, se basa en varias decenas de años de trabajo y discusiones científicas entre los filósofos nacionales dedicados a la filosoffa de la ciencia, los que ya desde los años 50 del siglo pasado conforman una comunidad cientifica integrada, que se ha mantenido hasta nuestros días. Los logros de esta comunidad se reflejan en el contenido de los artículos presentados, y en la lista de la literatura recomendadas ${ }^{29}$.

28 Sobre esta cuestión se tratará con cierto detalle en el ANEXO del presente artículo en el que ofrecemos 12 traducción algunas ponencias del reciente debate en el «Club Teórico" del Instituto de Filososfla de la ACR. sobre el tema: ¿Es boy dia necesaria la filosofia?

29 Dobronravova, I. S. (Doctor en filosofía, catedrática de filosoffia y metodología de la ciencia Universidad Nacional de Kiev "Tarás Shevchenko». "Intervención en la Mesa redonda virtual sobre la Nueva Enciclopedia Filosoffican, en Voprosy Filosofii, n. ${ }^{\circ}$ 1, 2003. p. 11. 
No es por lo tanto un hecho casual que una de las secciones más ampliadas y renovadas haya sido aquella que refleja los resultados del desarrollo de la filosofia y la historia de la ciencia en los siglos XIX, XX y en la que se ofrece una detallada exposición de temas como "Filosofia de la Ciencia», "Filosofia de las matemáticas" o "Filosofia de la Técnica", etc.

Como resultado de este tipo de trabajo colectivo el diccionario de términos sobre el pensamiento filosófico de ciertos países e incluso regiones ha sido prácticamente renovado. Tal es el caso, por ejemplo, de la filosofia Oriental y en ella de países como la India o la China, lo mismo que en el caso de algunos países del Mundo árabe. Por cierto, que en la exposición del pensamiento filosófico ruso desde el siglo XVIII hasta nuestros días también encontramos cambios radicales tanto en el contenido y en la valoración de los problemas planteados, como en la incorporación de muchos nombres de filósofos que habían sido borrados de la historia de la cultura del pals por motivos ideológicos o políticos. Parece evidente, por lo tanto, que entre los resultados positivos que han contribuido, de cierto modo, al éxito de esta obra se debe mencionar su carácter abierto, matizado por el hecho ampliamente reconocido de que todos los artículos que la integran han sido el resultado de una amplia discusión, en la que han prevalecido los criterios "científicos" y filosóficos de la investigación teórica. Una realidad que el lector más exigente puede valorar y agradecer al

«encontrar en ella algo más que respuestas aisladas y dispersas dictadas por opiniones subjetivas sobre las cuestiones que le pueden interesar, descubrirá también concepciones profundamente meditadas, un sistema de conocimientos sobre todos los problemas filosóficos de interés de la actualidad" ${ }^{30}$.

Queremos dejar claro que al anunciar en estas breves notas la publicación en Rusia de la Nueva Enciclopedia Filosffica, con ello sólo pretendemos destacar que se trata de un importante documento cuyo conocimiento y estudio es imprescindible para comprender el clima intelectual y la evolución del pensamiento filosófico de este país en la actualidad. Como muestra el período trans-

30 MAMCHUR, E. A. (doctora en ciencias filosóficas jefe del Sector problemas filosóficos de la fisica del I. de F. de la ACR.). "Intervención en la Mesa Redonda virtual sobre la NEF.", en Voprosy Filosofi, n. ${ }^{\circ} 1.2003$, p. 10. 
currido desde su publicación hace apenas dos años, el libro ha sido bien recibido, no sólo por la crítica especializada, sino por aquellos sectores de la cultura y la vida política que en su actividad práctica se sienten obligados ha mantener con la filosofía unas relaciones de convivencia real. Durante este tiempo el libro no solamente ha recibido elogios, sino que ha sido sometido a una crítica constructiva que sin duda contribuirá a mejorar en el futuro su estructura y contenido. Por esto, antes de pasar al último tema quisiéramos mencionar algunas opiniones pronunciadas en la "Mesa redonda virtual" organizada por la revista "Voprosy Filosofii», que en cierto sentido pretenden resumir lo tratado durante varios números. Pertenecen a destacados representantes de la vida política , científica y religiosa del país los que en sus intervenciones destacan y valoran la importancia de esta Enciclopedia.

Seleznev G. N., (Presidente de la Duma del Estado de la Asamblea Federal de la Federación Rusa) en su intervención afirma que la publicación de esta Enciclopedia es un suceso de dimensión estatal, un libro que fomenta la unidad que hoy día tanto se necesita en el país, pero "que no se puede crear sin recurir a los problemas que son competencia de la filosofia». Añade que si respecto a la filosofía él es tan sólo un lector interesado, no obstante se atreve a dar una valoración a la que tiene derecho como político y ciudadano, señalando ante todo el espíritu humanista que la inspira y la beneficiosa influencia que ejerce sobre sus lectores. Concluye felicitando a los autores y editores por el trabajo realizado en el que se han evitado los extremismos, tanto en la exposición de la filosofía religiosa de Rusia como en la valoración del pensamiento democrático incluido el marxista y en la que se percibe la sabiduria filosófica y la sensibilidad moral, lo que tiene un valor incalculable. Los cuatro tomos de la enciclopedia representan, según su opinión, un importante logro científico ${ }^{31}$.

Osipov Yu. S. (Académico, Presidente de la Academia de Ciencias de Rusia) En su intervención señala que la creación de la Nueva Enciclopedia filosófica constituye un éxito notable de la ciencia nacional humanista y un importante suceso en la vida cultural. Destaca también, que en la compleja situación actual cuando la humanidad se ve agobiada por los difíciles problemas globales el papel de la filosofía, que siempre ha sido y seguirá siendo una institución mediadora insustituible en las interrelaciones de las diferentes formas del saber, es cada vez

31 Ver Selezhnev, G. N. "Sobre la publicación de la Nueva Enciclopedia Filosófica», en Voprosy Filosofli, n. 4 . 2003, pp. 14-15. 
mayor. Por lo que uen estas condiciones no se puede prescindir de la filosofia y la racionalidad cientifica». Estas, según su opinión, están llamadas a encontrar una solución a los problemas que, con el impreciso término de globalización, se plantean ante las diferentes civilizaciones y culturas que integran la humanidad.

Destaca a continuación que la creación de una obra tan voluminosa en la que han participado varios centenares de especialistas de distintas instituciones ha exigido, además de la solución de los problemas exclusivamente científicos y metodológicos, también enormes esfuerzos organizativos y soluciones no triviales. El Instituto de Filosofía de la ACR. ha resuelto con éxito esta tarea en un tiempo bastante breve y sin abandonar sus programas de investigación.

"Nuestros filosofos han mostrado en este caso las cualidades más positivas de los científicos del país: su sentido de la profesionalidad y el trabajo abnegado. Ahora ante nosotros se plantea a nivel estatal la tarea de preparar la Enciclopedia Nacional Rusa. Yo creo que la experiencia de los filósofos ayudará en la realización de este proyecto» ${ }^{32}$.

Filaret (Mitropolita de Minsk y Sluzk, Patriarca Exarca de Bielorrusia, Presidente de la Comisión teológica del Sínodo) Reconoce que el inmenso trabajo realizado para la elaboración de la Nueva Enciclopedia Filosófica es un testimonio de que el Instituto de Filosofía ha culminado con éxito la elaboración de una obra que será un libro de cabecera para los especialistas y para la juventud que se interese por la filosofía.

"Como presidente de la Comisión teológica del Sínodo de la Iglesia Ortodoxa quiero testimoniar con satisfacción que los creadores de la Enciclopedia han puesto de manifiesto un enfoque objetivo de los temas de la teología y la filosofia de la religión, han mostrado que la religión ha sido un importante factor, que debe ser considerado para comprender correctamente la historia de la filosofía europea incluida la rusa... Todo esto, es un testimonio de que el diálogo de contenido cada vez más amplio entre la filosofía y la reología es un diálogo útil y perspectivo».

Y concluye señalando, que en una situación en la que los intereses de la población por las cuestiones de la concepción del mundo encuentran serios obs-

32 Osipo Yu, S. Op. cit. pp. 15-16. 
táculos, espera que la colaboración del riguroso pensamiento filosófico con el no menos riguroso pensamiento teológico hará posible elaborar nuevas orientaciones que permitirán el mutuo enriquecimiento de estos en bien de la sociedad.

"Tengo la esperanza de que la experiencia de colaboración acumulada por la Comisión teológica del Sínodo y el Instituto de filosofía de la ACR. continuará en el futurom ${ }^{33}$.

El examen defilosofía del doctorado: un cambo radical

Otro de los hechos más recientes y significativos que caracterizan los cambios que están teniendo lugar en Rusia en el campo de la filosofla durante los últimos años está vinculado a la decisión de la "Comisión Superior de Grados" cientificos de modificar el contenido del examen de filosofia que durante toda la época soviérica había sido imprescindible para obtener el grado de doctor en todas las ramas del saber científico. Un examen cuyo programa, elaborado en la etapa soviética, tenía un carácter sumamente ideologizado y exigía de todo aspirante a dicho grado el conocimiento de los fundamentos del marxismo y su filosof́a en su versión oficia el materialismo dialéctico e histórico. En la nueva Rusia el carácter anacrónico del viejo programa de estudios filosóficos y su desvinculación con los cambios acontecidos en la vida del país y con la situación real existente en la filosofía y en la ciencia estaba siendo duramente criticado y en muchos casos simplemente rechazado como un lastre obsoleto e innecesario. En la práctica real su contenido se había ido modificando poco a poco en un proceso espontáneo en el cual cada Consejo científico intentaba por su cuenta y riesgo cambiar o simplemente ignorar los temas y cuestiones cuyo contenido ideológico y dogmático no correspondían evidentemente a los nuevos cambios acontecidos en la filosofía. Por otra parte el contenido del curso se intentaba actualizar ad hoc con un aumento de los temas relacionados con la historia de la filosofia y los llamados problemas filosóficos de ciencia, temas que ya en las últimas décadas del poder soviético se habían desarrollado con cierto éxito y con frecuencia en velada oposición a los planteamientos del materialismo dialéctico dogmatizado cuyo anacronismo se puso en clara evi-

33 Filaret. Op. cit. pp. 16-17. 
dencia por su nefasto papel de apoyo a las conocidas tendencias anticientíficas que como la presunta "biología antigenetista" del nefasto T. D. Lysenko intentaron oponerse al desarrollo normal de la ciencia (la genética, la cibernética, la química cuántica) argumentando que estas contradecían los principios de la dialéctica materialista y eran engendros del "Idealismo imperialista reaccionario». Argumentación que contó no sólo con la aprobación de conocidos filósofos, sino con su apoyo entusiasta. Pero que se encontró simultáneamente con la oposición de muchos otros filósofos, estimulando el desarrollo "alternativo" de los temas y problemas relacionados con la filosofia de la ciencia.

Después de la desintegración de la Unión Soviética en la enseñanza de la filosofía a este nivel se crea una situación en cierto sentido cabtica e insostenible y se plantea la necesidad urgente de actualizar y renovar los programas de estudio de la filosofía adaptándolos a las nuevas realidades. Hay que tener presente que en la última década del siglo pasado y a pesar del bache inicial de principios de los 90 , el proceso de preparación de cuadros científicos muy pronto se recupera y hoy día en Rusia se defienden más tesis doctorales que en toda la Unión Soviética, a pesar de que en la actualidad la población del país es casi dos veces menor.

Ante la gravedad del problema la "Comisión Superior de Grados" hace unos años crea un grupo de trabajo, si queremos una subcomisión, que bajo la dirección del vicepresidente de la A.C.R el académico V. N. Kudriavzev organiza una amplia discusión del problema y después de amplias consultas con los institutos académicos, las universidades y otros centros de enseñanza superior toma la decisión de modificar radicalmente el contenido del examen de filosofía, que desde el año 2003 debe definirse como Filosofia e historia de la ciencia y en el cual, según el vicepresidente de la ya mencionada "Comisión" y también de la A.CR Koslov V. V. además de mantenerse las características humanistas del examen de filosofía general se acentuarán sus vinculos con la historia de aquellas ciencias concretas en el ámbito de las cuales se defendían las tesis de doctor, prestando una singular atención a los problemas de la lógica del desarrollo de las diferentes ciencias y la metodología de los descubrimientos teóricos y las innovaciones en las diferentes ramas del saber. La implantación se estableció desde el año 2003.

El hecho de que el tiempo establecido hasta el inicio de los exámenes según el nuevo programa fuera tan limitado se debía, en cierta medida, al hecho ya mencionado de que los problemas de la filosofía y la historia de la ciencia ha- 
bían experimentado ya desde la etapa soviética un rápido y fructífero desarrollo cuyos resultados positivos en la etapa actual son más que evidentes ${ }^{34}$. En el país ya existe una extensa literatura sobre estos temas y un numero cada vez mayor de especialistas bien preparados. Posiblemente se pueda incluso hablar de que se ha gestado una tradición en los estudios de los problemas de la filosofía de las diferentes ciencias y el estudio de la (las) historia(s) del saber científico está muy avanzado en algunas disciplinas; y también de que en la actualidad ya se dan las posibilidades reales necesarias para su realización, debido entre otras cosas al alto nivel de organización académica que permite planificar y emprender un serio trabajo colectivo que incluye desde la elaboración de los programas de estudio, los manuales y otros materiales didácticos hasta su publicación y divulgación. Para que todo esto se lleve a cabo operativamente la "Comisión Superior de Grados» ha creado un grupo de trabajo que dirigen G. A. Mesiezev (Vicepresidente de la ACR) y V. S. Stiopin (Director del Instituto de filosofía de la ACR.) y que según el ya citado V. V. Koslov ya ha iniciado la compleja labor de poner en marcha un programa que presupone en el plano organizativo los siguientes pasos iniciales en el trabajo de este grupo:

"Nuestro grupo de trabajo ha decidido cumplir su misión en dos etapas. En primer lugar nos dedicamos a la elaboración de los programas en cada dirección. Cuando estos programas sean estudiados, aprobados y aceptados, se iniciará la segunda etapa que debe concluir con la edición de una serie de materiales didácticos, cuyo status aun no se puede puntualizar. Los manuales deben abarcar todas las direcciones que suman 24: desde la filosoffa de la ciencia hasta la historia de la pedagogía. El volumen de cada manual será de entre diez o quince pliegos. Esto no significa que cada candidato a doctor deba estudiar los 24 libros. Sólo, el primero el de Filosofia de la ciencia será para todos. Este manual tendrá a su vez dos partes: la primera tratará sobre los problemas de la filosofia en general y la segunda de los problemas filosóficos de cada ciencia concreta, que serán agrupados de cierto modo. La filosofia de las matemáticas será especialmente tratada en un manual y un lugar específico lo ocuparán los problemas filosóficos de las humanidades. Estos manuales están en proceso de preparación en el Instituto de Filosofía. Los restantes 23 manuales estarán dedicados a la historia de las diferentes disciplinas concretas y los aspirantes sólo se examinaran por uno de estos.

34 Sobre este tema ver: BURGUETE RICARDO «La filosofla de la ciencia y la filosofía de la técnica en Rusia (1995-2000m, en Endosa. Series filosofficas, n. ${ }^{\circ}$ 13, 2000, pp. 91-119. 
Esta lista de manuales se abre con los manuales de historia de las matemáticas, de la mecánica, la física y concluirá por los de historia de las humanidades. También se dedicará un manual a la historia de la filosofia ${ }^{35}$.

Como podemos ver por esta larga cita esto se refiere, solamente y en lo fundamental, a los aspectos formales del problema. Evidentemente algunas cuestiones de contenido sólo se pueden intuir, debido a que su valoración sólo será posible cuando los primeros programas y manuales se presenten para ser discutidos por la comunidad científica.

Como se puede ver, el tema de este examen rompe por su contenido la rutina del anterior establecido oficialmente por funcionarios incompetentes y sancionado por los órganos ideológicos del Partido Comunista, que lo consideraba un elemento básico de la ideología oficial y como tal dependía de las imposiciones del correspondiente sector del Comité Central de este partido. Sector que después de la publicación en 1938 del "Curso breve de Historia del Partido bolchevique" convierte su cuarto capítulo "Sobre el materialismo dialéctico e histórico" en el Manual universal de filosofia marxista apto para todos los niveles, incluidos los aspirantes al grado de doctor. Como se había anunciado que su autor era el propio Stalin: "Su texto fue inmediatamente carismatizado ideológicamente». Y desde este momento

"el materialismo dialéctico e histórico en su calidad de única y verdadera filosofía se contraponía a todos los puntos de vista filosóficos sobre el mundo y recibía la definición inobjetable de filosofía marxista leninista. Filosofía que desde entonces se convirtió en una materia de estudio obligatorio desde la amplia red de la llamada "educación partidista" y naturalmente en todos los niveles de enseñanza superior de la URSS" ${ }^{36}$.

El estudio de la Filosofia y la Historia de la Ciencia pone fin a la filiación ideológica del examen precedente de filosofia. Este se centra ahora en el análisis de las relaciones entre la filosofía y la ciencia. Ahora el aspirante a doctor aborda los problemas filosóficos con la metodología y la creatividad del cien-

35 Koslov, V. V. "Sobre el nuevo examen de filosofia», en Cuestiones de la bistoria de las ciencias naturales $y$ la técnica, n. ${ }^{\circ} 2,2002$, p. 369.

36 Mijailov, F. T. «La educación y el poder», en Voprosy Filosofi, n. ${ }^{\circ} 4,2003$. p. 33. 
tífico. La filosofía ya no es para él algo extraño que debe aprender de memoria sin saber para qué, pues se convierte inevitablemente en un elemento de su propia investigación. Por otra parte, parece evidente también que la Comisión Superior de Grados al encargar la elaboración de los nuevos programas y mariuales a conocidos especialistas, que por su trabajo precedente en el campo de investigación de la filosofla y la historia de la ciencia, y por su experiencia en la enseñanza de la filosofia a este nivel conocen las inquietudes de los futuros alumnos, no sólo intenta ganar un tiempo precioso, sino que ha confiado definitivamente esta labor a la comunidad científica especializada, que será la encargada de aprobar o rechazar el resultado final del nuevo programa en introducir en él las correcciones pertinentes.

Anexo

Dos enfoques de un tema polémico: ¿Es hoy día necesaria la filosofia? ${ }^{37}$

Mientras los hombres continúan pensando y la capacidad de pensar siga siendo una necesidad de primer orden para la plenitud de su vida, la filosofla será necesaria y reclamada.

Tolstij, V. I. (Doctor en ciencias filosóficas, investigador cientifico principal del I. de F de la A. C. R., Presidente del Club de discusiones LA PALABRA LIBRE)

El presente tema está ya maduro desde hace tiempo, si no está ya "pasado». Quiero recordar que a principios de los años 90 se inició un potente ataque contra la filosofía, como si esta fuera el bastión de la ideología soviética, que por cierto no se había destacado en nada notorio. Ustedes recordarán que entonces este ataque lo rechazamos y dedicamos dos sesiones a la discusión del tema "El marxismo - a favor y en contra-". Incluso llegamos a editar un libro con el mismo título, el cual, según mi parecer, mitigó en cierta medida la critica indiscriminada de la filosofia en general y en particular de la filosofia mar-

37 El texto original integro de esta discusión se publicará en el Anuario $L A P A L A B R, 4$ LIBRE Crónica intelectual 2003. Las (intervenciones que hemos traducido con el consentimiento de los dirigentes del CLUB y los autores para nuestra Revista) se han realizado del texto ruso entregado a la imprenta para ser publicado a fines de este ańo. 
xista. Más tarde se inicia una nueva "ronda" de intromisiones vinculada a los intentos de los ć́rculos poderosos «no académicos» de liquidar el examen de filosofía para los aspirantes a doctor. (Sobre esto nos puede hablar con conocimiento de causa Viacheslav Semiónovich Stiopin que ha empleado no poco trabajo y energía para rechazar estos ataques). Hoy día este tema ha recibido nueva resonancia, en un plano que tiene, como yo diría, una clave constructiva $y$, por ello, la respuesta a la pregunta formulada es necesaria e importante debido a causas y motivos creativos.

La pregunta está planteada en forma directa, como se hubiera dicho en otros tiempos con "franqueza bolchevique". Lo hemos hecho así teniendo conciencia de ello. Espero que ninguno de los aquí presentes tenga dudas de que hoy día la filosofía "es necesaria", aunque otra cosa es, que para alguien no sea en general «necesaria» e incluso molesta para llevar a cabo ciertos asuntos que no la necesitan para nada. Pero que la filosofía es necesaria se puede confirmar con muchos ejemplos y argumentos. Sólo mencionaré dos.

Como sabemos, inicialmente a nuestros reformadores liberales les ha podido parecer que era suficiente proclamar la prioridad de los valores generales humanos y el paso del totalitarismo a la democracia, de la economía planificada a la mercantil, para que la causa de la reforma del país experimentara un impulso capaz de iniciar su transfórmación y renovación. No obstante, muy pronto se descubrió que se necesitaba también «cierta idea nacional" que cohesionara la sociedad y permitiera el imprescindible apoyo de la población a las reformas. En lugar del rechazado sistema soviético de valores se requería otro nuevo que correspondiera a la particularidades de nuestra civilización, a las tradiciones históricas y a la mentalidad nacional del país. ¿Pero acaso esta tarea historiosófica y mundo edificante podía resolverse sin la filosofía? A mi modo de ver, la respuesta es evidente

Algo similar ocurre con el tema o el problema de la globalización, que en la literatura globalística se ha visto limitado por la mayoría de los investigadores a los procesos comunicativos exclusivamente tecnológicos y se interpreta como un movimiento hacia un "mundo sin fronteras", en el espíritu de una nivelación cosmopolita del significado de los intereses y la soberanía nacionales y la diversidad cultural. De este modo los partidarios de las ideas de un "mundo unipolar", ignorando la compleja dialéctica de lo general, lo particular y lo individual, están hoy día intentando privatizar la necesidad objetiva de la unidad y la integración, planteando y explotando el problema desde las posi- 
ciones de los poderosos. Según mi punto de vista un papel funesto, similar a una cortina de humo, están cumpliendo en esto los intentos de identificar la globalización con sus manifestaciones y consecuencias económico-tecnológicas. Aquí, evidentemente, se percibe la necesidad de un enfoque filosófico de este fenómeno, que no se debe dejar en manos de los economistas, sociólogos y politólogos. No es una casualidad que la formula, en principio correcta, "pensar globalmente y actuar localmente» no encuentre su realización o reciba en la práctica una aplicación perversa. No está claro lo que significa pensar globalmente en las condiciones de una crisis paradigmal de la civilización mundial. Sin la filosofía aquí no hay nada que hacer.

Los ponentes son bien conocidos. Sólo quiero señalar que Vadim Mijailovich Meshuev es uno de los promotores de la discusión de este tema, en lo que ha encontrado con mi apoyo activo. Viacheslav Semionovich Stiopin es autor de una obra fundamental "El pensamiento teórico» y del artículo "La filosofia" en la Nueva Enciclopedia Filosófica, quién sino él puede ser uno de los «impulsores» de nuestra discusión.

Stiopin, V. S. (Académico, Director del Instituto de Filosofía de la A.C. R., Presidente de la Sociedad Filosófica de Rusia)

¿Es hoy día necesaria la filosofía? Yo hubiera formulado esta pregunta de otra forma: ipara qué es necesaria en general la filosofía y en qué épocas ésta empieza a cumplir una función de importancia vital para la sociedad?

Pero establezcamos primero cómo entendemos la filosofía. Existen muchas definiciones de la filosofía. Tenemos la definición de Engels que aprendimos en las universidades y que decía, que la filosofía era la ciencia sobre las leyes más generales de la naturaleza, la sociedad y el pensamiento. Una definición cientista, que a pesar de incluir algunos elementos y aspectos del saber filosófico era, en general, limitada. Esto se debía a que existen esferas del filosofar que difícilmente se pueden considerar variantes del saber científico. Por ejemplo la filosofía de Dostoevsky, Tolstoy, Sócrates, Rosanov, las doctrinas teológicas, etc. Pero en la filosofía existen simultáneamente capas del saber y procedimientos de pensamiento y razonamiento o, como ahora suele decir la moda, tipos de discurso, que encajan perfectamente en la definición de ciencia.

Es necesario, también, establecer a qué se dedica la filosofía y para qué es necesaria en la sociedad. Han existido civilizaciones en las que se ha prescindido de la filosofía. No ha existido, por ejemplo, en el antiguo Egipto, a pesar de 
que si existía una concepción del mundo. La filosofía y la concepción del mundo no se deben confundir. La filosofía es el núcleo teórico de la concepción del mundo. Se conocen también las características de la filosofía establecidas por Hegel y que con pequeñas modificaciones encontramos en C. Marx, para los que la filosofía es el alma viva de la cultura, la quinta esencia de ésta, la época expresada en el pensamiento. En este enfoque la filosofía se vincula a la cultura y se plantea la cuestión sobre las funciones de la filosofía en la cultura.

En los fundamentos de la cultura, de cualquier cultura, existe un sistema específico de sentidos de la concepción del mundo, representados por un sistema de categorías que yo defino como los universales de la cultura. En ellos queda fijada la comprensión de lo que son: el hombre, la naturaleza, la actividad humana, el espacio y el tiempo, la causalidad y también, lo que son la libertad, el bien y el mal, la vida y la muerte, el trabajo, la vergüenza, el honor y la justicia. Estas son las categorías de la cultura, y para el hombre socializado en una determinada cultura éstas conforman el orden categorial de su conciencia. Cada individuo comprende los sentidos de los universales de la concepción del mundo de su cultura, debido a que con la educación y la socialización estos penetran en la trama de nuestra conciencia. Pregunte al hombre de la calle, qué es la justicia y no os dará su definición, pero comprenderá lo que es justo, os ofrecerá ejemplos y os dirá si tiene un vecino justo o injusto etc. Tiene una comprensión, pero no un saber reflexivo. El no piensa sobre la justicia, la vive y para él es un valor. Esto significa que los universales de la cultura son, simultáneamente, valores básicos. En su intervinculación e interacción nos ofrecen un cuadro integral del mundo vital del hombre, de lo que definimos concepción del mundo. Esta incluye por definición la percepción, la vivencia, la comprensión y la asimilación del mundo, en las que no sólo está presente el componente racional, sino la actitud emocional del hombre hacia el mundo.

Es importante comprender y tener presente que los universales de la cultura no están localizados, penetran todos sus espacios, se manifiestan en el lenguaje, en la conciencia común, en el arte, en el pensamiento artístico y en la conciencia científica. Representan de por sí formas categoriales, por medio de las cuales la compleja experiencia humana en constante acumulación se selecciona y se integra a la tradición cultural y se hereda por las generaciones venideras.

Por la estructura de su contenido los universales son complejos, por el hecho de que está incluye en sí tanto el componente general humano como aquel que expresa las particularidades de una u otra cultura. Debido a este 
componente la cultura china del siglo III a.C., por ejemplo, se distingue de la cultura de la Antigua Grecia. En ellas el ser y el no ser, la actividad, el movimiento se entienden de modo diferente etc. Por último, en los universales de la cultura hay un componente más que expresa la actitud individual del hombre hacia el mundo y está condicionado por la experiencia vital por él acumulada. Este componente surge debido a que los universales de la cultura se asimilan por los hombres y se convierten en estructuras de sus conciencias de tal modo que cada individuo "adorna» el tejido de las categorías con las particularidades de su propia experiencia vital. Los universales de la cultura se presentan como una base sobre la cual surgen y con la que concuerda todo el conjunto de programas de actividad, conducta y comunicación que constituyen el "cuerpo de la cultura" los conocimientos, las vivencias, las creencias, los planteamientos de la concepción del mundo, las valoraciones, modelos de conducta y actividades, etc. Son estos los que garantizan la reproducción de uno u otro tipo de sociedad, se trasmiten como su código genético-cultural. Los universales funcionan como singulares genes de los organismos sociales.

Desde este punto de vista la filosofía es una reflexión sobre los fundamentos de la cultura y los universales de su concepción del mundo, pero no son idénticos a estos. En primer lugar, el conocimiento filosófico simplifica y esquematiza de tal modo los universales de la cultura, que muchas capas de los sentidos vitales, sobre todo aquellos que están vinculados a las vivencias emocionales del mundo, quedan fuera del análisis filosófico o pasan a un segundo plano. En segundo, la filosofía transforma los universales de la cultura en objetos específicos ideales, en esencias abstractas, con las que empieza a operar del mismo modo que los matemáticos operan con los números, las figuras y las funciones. De este modo la filosofia descubre nuevas propiedades, nuevas relaciones sin dirigirse directamente a la realidad. La filosofía construye nuevos sentido de las categorías y, por ello, sale con frecuencia fuera de los marcos de una u otra tradición cultural, enfocando los sentidos por ella descubiertos hacia el futuro. A qué futuro -el filosofo no lo sabe-. Pero ocurre con frecuencia, que pasado algún tiempo se establece de repente que lo descubierto por el filósofo ha sido utilizado.

Ofreceré un ejemplo: En su tiempo J. Locke al criticar al absolutismo desarrollando los principios del liberalismo fundamentó las ideas del contrato social, de la división de poderes y los derechos naturales del hombre. Aproximadamente después de 100 años Jeffersón y otros padres de la constitución americana recurrieron a las ideas de Locke y las utilizaron conscientemente. $Y$ un ejemplo más. 
Cuando en la antigua Grecia se forma el nivel teórico de la meditación filosófi$\mathrm{ca}$, el problema de la relación de la parte y el todo se plantea como un problema teórico. Entonces las respuestas más evidentes desde el punto de vista de la tradición cultural existente fueron las siguientes: el todo consiste de partes, las partes se unen en un todo y el todo se puede dividir en partes. Pero la filosofía no se limitó ni conformó con estas respuestas, analizando todas las variantes de este problema teórico. La primer variante - el todo se divide en partes hasta un límite. Estos fueron Demócrito y Epicuro - la atomística. La segunda variante —el todo se divide en partes sin límites. Este fue Anaxágoras. Pero se conoce una tercera variante, a primera vista una variante alocada —el todo no se divide en general en partes, el mundo es uno e indivisible.

Estos fueron los eleáticos. Pero entonces surgen nuevas cuestiones: si el mundo es indivisible el movimiento no puede existir. La respuesta de Zenón - como el movimiento no existe, esto significa que los sentidos nos engañan. $\mathrm{Al}$ intervenir con sus famosas aporías Zenón inicia la fundamentación de estos planteamientos. Aquiles no alcanzará la tortuga, el puente no se podrá pasar. Desde el punto de vista del sentido común estas conclusiones son absurdas. Pero en estos razonamientos se plantean problemas muy profundos. Por ejemplo, ¿qué significa pasar el puente? Esto implica que se debe pasar un tramo que incluye un número infinito de puntos. Para pasarlo es necesario pasar prímero la mitad, después la mitad de la mitad y la mitad de esta mitad etc., pero siempre quedará un pequeño tramo que también constará de un número infinito de puntos ¿Qué es lo que estaba palpando Zenón? En el ámbito de los razonamientos filosóficos estaba planteando un serio problema. Si se considera que un segmento de cierta magnitud está constituido por un número infinito de puntos ¿Cómo se puede entonces demostrar que la parte es menor que el todo? La parte lo mismo que el todo es un número infinito de puntos. ¿Cómo comparar los infinitos? Este problema ha resurgido dos mil años después de Zenón en las matemáticas. G. Frege lo intentó resolver y a esto se dedicó G. Cantor. Se trata del problema de la conmensurabilidad de los infinitos. Con él tropezaron Russel y Whitehead, cuando en la teoría de los conjuntos resolvían el problema de las paradojas .

Además, por cierto, la aporía «Aquiles no alcanzará a la tortuga» planteaba también un problema no trivial. Si esta aporía la aplicamos al movimiento de las micro partículas en el miero-mundo y si tomamos en cuenta los efectos contemporáneos de la teoría de la relatividad, entonces son posibles situaciones en que las partículas que se aceleran (Aquiles) no pueden alcanzar las par- 
tículas que se mueven con una velocidad finita (la tortuga). Supongamos que Aquiles es el protón, que se acelera y adquiere paulatinamente una velocidad cada vez mayor. Supongamos que la tortuga es el neutrino, su masa es menor y se mueve con velocidad constante, cercana a la velocidad de la luz. Si en esta situación empezáramos a acelerar el protón su masa durante el movimiento aumentaría. Esto significa que Aquiles para lograr su aceleración debería emplear cada vez mayores esfuerzos. Al acercarse a la velocidad de la luz la fuerza de su aceleración tendería al infinito. Esto significa que existe un límite en donde Aquiles ya no está en condiciones de aumentar su velocidad. Es más, si Aquiles tuviera en sus manos una regla por medio de la cual pudiera medir la distancia que le separaba de la tortuga, descubriría horrorizado que esa regla al acercarse a la velocidad de la luz disminuía de tamaño y se podía colocar en la distancia que le separaba de la tortuga más veces que la regla precedente. Esto significa que la distancia entre él y la tortuga en su sistema de medición no había disminuido sino aumentado. Tales son las sorprendentes conclusiones de esta aporía, si la aplicamos teniendo en cuenta los descubrimientos de la física contemporánea.

Como se puede ver en las aporías de Zenón ya fueron planteados en forma abstracta ciertos problemas que se adelantaban a su siglo. He recordado estos dos ejemplos para mostrar de qué modo la filosofía puede rebasar los marcos de su tradición cultural y generar sentidos que en el futuro pueden ser necesarios en la ciencia, en la política y en otras esferas de la actividad cultural.

La filosofía somete a su análisis crítico los universales de la cultura. Y surge la pregunta ¿Para qué sirve esto? Suele ocurrir que se utilice para justificar una situación cultural establecida. Desde el momento en que el filósofo afirma que los sentidos vitales representados por los universales de su cultura son los mejores, divinos, tienen un carácter absoluto y no se pueden imaginar mejores, desde ese momento está justificando el modo de vida existente y cumple la función de ideólogo. La filosofía es portadora de una función ideológica cuando justifica el modo de vida imperante o aquel que ella misma "inventa" y presenta como ideal. Pero la filosofía no se reduce a esta función ideológica. En ella existe un aspecto alternativo: la generación de nuevas ideas y nuevos sentidos de la concepción del mundo que rebasan los marcos de su cultura. Este análisis es necesario no para perpetuar los fundamentos precedentes de la vida social, sino para contribuir a los cambios sociales: En este aspecto tiende preferentemente hacia la ciencia y la creatividad. 
En la vida de la sociedad surgen, periódicamente, unos estados cuando aquella no está en condiciones de encontrar respuestas a los retos históricos e intenta conservar el modo de vida precedente, cuando los sentidos de los universales de la cultura ya no son capaces de garantizar la coexistencia e interacción de los tipos y modos de actividad, conducta y relaciones humanas. La experiencia individual de muchos individuos ya no concuerda con los sentidos de los universales establecidos y, entonces, el hombre empieza a vivir de tal modo que hace una cosa, piensa otra y dice una tercera. Se trata de estados de ruptura en el modo de vida, la primera señal de que algo no está en orden en los fundamentos mismos de la concepción del mundo, en las orientaciones fundamentales de la vida. Estos se rompen, creando esa situación que ha sido expresada con tanta exactitud y profundidad por Shakespeare en "Hamlet» «Se ha roto el vínculo de los tiempos». Vivir en una situación en la que se destruyen los sentidos de los viejos universales y cuando aún no existen los nuevos es muy difícil. Es, precisamente, en estas épocas cuando los propios hombres son los que plantean los problemas de la concepción del mundo. Cuando estos, por ejemplo, se acercan a cierto sabio que puede ser Sócrates y le dicen, Sócrates enséñanos a vivir virtuosamente. Y entonces Sócrates responde ¿pero sabéis qué es la virtud? Veamos de que se trata. $Y$ es entonces cuando se inicia el análisis de este concepto. Se puede considerar que es desde este momento que se inicia el trabajo filosófico. Es, precisamente, para lo que se necesita la filosofía. Ella aclara los sentidos establecidos de los universales de la concepción del mundo, los investiga y los presenta al juicio de la razón. Al criticar los viejos sentidos elabora otros nuevos y se los ofrece a los hombres. Pero si estos sentidos no se pueden implantar en su tiempo la filosofía los orienta hacia el futuro. En los períodos de ruptura de la historia social siempre surgen las cuestiones sobre la estrategia del desarrollo, sobre las ideas, los procedimientos de cohesionar la sociedad, sobre qué conservar y qué desechar del equipaje de las tradiciones. Todas estas cuestiones, preguntas y respuestas no las debe solucionar, necesariamente el filósofo profesional. No obstante, aquel que se dedica a este trabajo se ha internado en la esfera del conocimiento filosófico, ha empezado a filosofar. La filosofía es necesaria para esto.

Si la sociedad no cambiara y no se desarrollara la filosofía no sería necesaria. Para una sociedad que se reproduce a sí misma constantemente basándose en sus propios fundamentos y en la que los universales de la cultura son estables -la filosofía no es necesaria. La filosofía se necesita porque la sociedad cambia, y sin los universales de la cultura que son algo así como los genes del 
organismo social, su genóma, para que el organismo social cambie- es necesario cambiar los genes. La filosofía es uno de los factores mutagénicos de la sociedad, que constantemente aporta a la cultura las mutaciones.

Tolstij, V. I.-Viacheslav Semionovich ¿Pero porqué no la necesitamos nosotros?

Stiopin, V. S. - Si «nosotros" somos los que ostentamos el poder, no la necesitamos porque introduce mutaciones en la cultura, permite salir fuera de los marcos del modo de vida existente, de las tradiciones culturales. El filósofo se convierte en una figura peligrosa. ¿Para qué necesita el poder ciertas dudas sobre el carácter correcto del camino elegido? El filósofo, si se ha dedicado al trabajo teórico de "pronosticar", nunca ha sido una figura deseable para el poder. Pero cuando como ideólogo justifica lo que existe, entonces, si es necesario. Es por esto, que los poderes siempre han intentado reducir la filosofía a la ideología, convirtiendo al filósofo en un mero ideólogo, pero la filosofia y los filósofos siempre se resisten a esto. Ellos buscan nuevos sentidos vitales no sólo en las épocas de cambios, sino sistemáticamente, antes de que los períodos de ruptura tengan lugar en el desarrollo de la sociedad. En este plano la filosofía es una ciencia, similar, por ejemplo, a lo que Lelbniz definía como matemática —una ciencia sobre los mundos posibles. La filosofía es la ciencia sobre los posibles mundos de la actividad vital humana. Ella siempre propone, elabora algo que está dirigido al futuro, que algún día puede ser utilizado.

Si la sociedad es dinámica, entonces protege al filósofo y hasta le permite decir, desde el punto de vista del poder existente, todo tipo de "tonterías" que pueden ser utilizadas en el futuro, lo protege de los ataques, le permite fortalecerse en asociaciones profesionales y discutir profesionalmente sus problemas. Debido a que es en los marcos de estas discusiones donde nacen los nuevos sentidos de la vida, que se trasladan a la deriva como genes, incorporándose a la cultura, y cuando llegan las épocas de trasformaciones sociales radicales, entonces el filósofo pasa a un primer plano, e incluso después de muerto se convierte de repente en una persona muy conocida. Sus ideas "prematuras» empiezan a generar una crítica publicitaria y artística, doctrinas religiosas y políticas, en las cuales se diluyen con frecuencia de tal modo, que lo inicialmente surgido en la cúspide de la abstracción filosófica penetra en la interioridad de la cultura, se trasforma en los nuevos universales de su concepción del mundo. El camino de la asimilación filosófica del mundo es el siguiente: de los sentidos reales de los universales de la cultura al vuelo de la abstracción, la comprobación de la fun- 
damentabilidad y la fuerza vital de las nuevas ideas y por fin su internación en las profundidades de la cultura. Así está constituida la vida social y esta es la función de la filosofía. De aquí llego a la conclusión, de que la filosofía es necesaria allí y entonces, donde y cuando en la propia cultura tienen lugar cambios radicales. Es de este modo como se confirma su significado práctico.

Hoy día la humanidad está pasando por una de estas épocas en la que se quiebran todos los valores básicos de la civilización tecnogénica que ha generado las crisis globales. Y esto está teniendo lugar ante nuestros ojos: surge una sociedad de enormes peligros y tiene lugar una búsqueda de nuevos caminos para el desarrollo de la civilización. Este es otro tema, y yo podría demostrar que es imposible compaginar los ideales de la sociedad de consumo con las posibilidades de una salida de las crisis ecológica y antropológica en las que la civilización tecnogénica ha sumergido a la humanidad. Ahora se ha emprendido la búsqueda de nuevas estrategias y se crean puntos de crecimiento de nuevos valores en la ciencia y en la conciencia religiosa. Han aparecido, por ejemplo, teólogos protestantes que afirman que Dios no ha concluido aún la creación del mundo, que la evolución continúa y que la evolución es el propio Dios. Él crea los mundos y ha creado ya varios universos, en los que no existe la razón, pero en la creación ha dejado implícito el principio antrópico al haber creado un universo con el hombre y su razón. Por lo tanto somos responsables no sólo en la Tierra, sino por lo que ocurra en el universo. Estas ideas implican un nuevo cambio en la dogmática cristiana.

Inesperadamente en la ciencia se está ampliando el campo de sus aplicaciones a la concepción del mundo. Ciertas ideas de las culturas tradicionales, que antes se rechazaban como místicas, empiezan de repente a concordar con el cuadro científico del mundo y con las estrategias del desarrollo técnico contemporáneo. Sobre esto ya he escrito y he destacado tres circunstancias.

En primer lugar, que las culturas antiguas siempre percibieron y comprendieron a la naturaleza que rodea al hombre como un organismo vivo. La ciencia europea de la Época Moderna se inició con la impugnación de estas representaciones postulando una visión mecánica de la naturaleza como una maquina sometida a las leyes de la mecánica. Pero en la ciencia del siglo XX se consolida una nueva comprensión del medio natural del hombre como un ecosistema global, la biosfera, que constituye un tipo específico de organismo. Surge una resonancia inesperada entre la ciencia contemporánea y las culturas tradicionalistas. 
En segundo, en el desarrollo científico técnico contemporáneo empiezan a asimilarse activamente los sistemas complejos en desarrollo histórico, en los que está incluido el hombre. Estos sistemas son jerárquicos y en el proceso de su desarrollo son cada vez más complejos, aumentando el nivel de organización de sus elementos de tal modo que cada nuevo nivel actúa sobre los anteriormente existentes cambiándolos y reconstruyendo el sistema en una integridad nueva. Los sistemas en desarrollo histórico se caracterizan por su carácter abierto, por el intercambio con el medio circundante de sustancia, energía e información. A estos sistemas les son propias las características sinergéticas. Estos pasan históricamente por puntos de bifurcación, por estados de tránsito de fase en los que las acciones energéticas débiles pueden resultar decisivas para el desarrollo futuro del sistema. Tiene lugar una singular selección de los posibles escenarios del desarrollo del sistema y uno de los cuales se actualiza. A este tipo de sistemas pertenecen la mayoría de los objetos de las biotecnologías contemporáneas y de la ingeniería genética, todos lo objetos biológicos (los organismos, las poblaciones, las biogeocenosis, la biosfera) vistos desde el punto de vista de su desarrollo son objetos de las tecnologías informativas contemporáneas, es decir, de las complejas redes de ordenadores y la "telaraña mundial" INTERNET, los objetos sociales en desarrollo etc. La estrategia de la actividad con los sistemas en desarrollo limitan los procedimientos habituales de aplicación de la fuerza, la que tradicionalmente se ha considerado como una condición necesaria para la transformación de los objetos. El simple aumento de la aplicación de la fuerza sobre el sistema puede conducir a que este empiece a repetir unos mismos estados sin generar nada nuevo. Pero una débil acción, un simple pinchazo en el lugar espacio-temporal adecuado es capaz de conducir a la formación de nuevos niveles de organización, generando una integridad nueva estable.

Este tipo de estrategias en la actividad concuerda con los ideales de acción no violenta de la tradición cultural indú, con el principio «u-vey» de la antigua cultura china. Recordaré que el principio "u-vey» consideraba que el éxito en la actividad se conseguía con la mínima intervención en el curso del proceso, una intervención condicionada por la percepción de los ritmos del mundo que deben ser observados por el verdaderamente sabio. La alegoría del "sabio" que intentando acelerar el crecimiento de los cereales tiraba de sus tallos arrancándolos de cuajo, era una muestra de a donde conduce la violación del principio «u-vey».

Por último, en tercero, en la ciencia contemporánea se establecen nuevas relaciones entre la verdad y la moral. Las antiguas culturas orientales consideraban que la moralidad era una condición para el descubrimiento de la verdad 
(la verdad sólo está al alcance de aquel que ha recorrido el camino del perfeccionamiento moral). En la tradición cultural europea por contrario, primero la verdad y sólo después, o a partir de ésta, era posible la moralidad racional.

Estos dos enfoques alternativos se aproximan inesperadamente. En las situaciones de elección de uno u otro escenario del desarrollo de los sistemas complejos de dimensión humana es especialmente importante evitar los escenarios arriesgados, peligrosos para el hombre. Por esto los grandes proyectos científico-técnicos contemporáneos pasan necesariamente el examen pericial ético. Se crean comités de ética que dictan su veredicto sobre los programas tecnológicos y de investigación los que sin una valoración pericial ética positiva no reciben financiación.

Resulta que la ética interna de la ciencia basada en dos presunciones: «la búsqueda de la verdad" y el "aumento del saber verdadero" no es de por si suficiente para esto. Se necesitan regulaciones éticas complementarias que vinculen claramente la ética interna de la ciencia con los principios éticos humanistas.

Todo esto conforma los puntos de seguimiento de los nuevos valores de las primeras líneas del desarrollo científico-técnico. La búsqueda de nuevos valores también tiene lugar en la ética, sobre todo debido a los trabajos en la ética ecológica y la bioética. Esta búsqueda se lleva a cabo en el arte contemporáneo y también en la propia filosofía. El post modernismo actual refleja parcialmente este movimiento, pero lo interpreta preferentemente en el plano negativo y destructivo. Yo no veo que en él se elaboren nuevos sentidos, pero en determinados límites, la crítica de los universales de la cultura tecnogénica sí se vislumbran.

¿Pero acaso sería posible prescindir de la filosofía en la complejísima situación actual de crisis, cuando está en juego el destino de la civilización humana y cuando es evidente la necesidad de elaborar una nueva estrategia del desarrollo no sólo de unos u otros países, sino de todo el socium mundial globalizado? Evidentemente esto es imposible. Se necesita una nueva estrategia de la actividad vital humana, que ponga los fundamentos de la tradición cultural futura. Se trata de la búsqueda de un nuevo tipo de desarrollo civilizacional, que se realizará o por medio de la convergencia de la sociedad tradicional y la tecnogénica, o se encontrará un camino diferente, esto aún no está claro. La marcha tempestuosa del progreso tecnológico plantea muchos problemas nuevos, que aún debemos intentar comprender. Para aquellos que comprenden esta situación la pregunta « Es necesaria hoy día la filosofía? No surge. 
¡Parece evidente, que si el poder quiere elaborar una estrategia del desarrollo a largo tiempo se verá incluso obligado a apelar de una u otra forma al saber filosófico! Pero la mayoría de los que ostentan el poder no siente esta necesidad. ¿Porqué? Puede ser por el hecho de que la organización democrática concede al poder cuatro años para que pueda resolver tareas exclusivamente prácticas e inmediatas y para pensar cómo reelegirse una vez más. Este practicismo eclipsa con frecuencia la necesidad de pensar sobre una estrategia duradera del desarrollo. $\mathrm{Y}$ a pesar de que los políticos serios al resolver sus problemas nacionales se preocupan por lo que pasa en el mundo a nivel global, se necesita una elaboración detallada de los posibles escenarios del desarrollo global de la humanidad. Una labor que no puede prescindir ni de la filosofía ni de los filósofos.

Meshuev, V. M. (Doctoren filosofía; Colaborador científico principal del Instituto de filosofía de la ACR.)

La cuestión sobre si es necesaria hoy día la filosofía puede parecer el resultado de la imaginación a pesar de que en la filosofía se viene discutiendo desde hace relativamente bastante tiempo, aproximadamente desde la segunda mitad del siglo XIX. Para que la discusión sobre este tema en este auditorio también sea posible, es necesario aclarar el sentido de esta interrogante.

Evidentemente nadie pone en dudas que la filosofia, independientemente de que sea o no necesaria, realmente existe en nuestros días - por lo menos en la forma del Instituto de Filosofía en el que estamos reunidos, en la enseñanza de la filosofía, en la literatura filosófica que se edita y se lee por alguien y también, por cierto por un grupo específico de personas que a sí mismos se llaman filósofos-. Pero existir no significa ser necesarios. En el mundo existen muchas cosas de las cuales se puede prescindir. Se comprende que la filosofía es necesaria para los filósofos, los que bien o mal viven de ella, es necesaria para aquellos que se interesan por ella, a pesar de que se puede tener interés por cosas que no tienen una relación directa con la vida de hoy, por ejemplo, los monumentos antiguos. Nadie pone en discusión el derecho de la filosofía a existir como objeto de afición personal e interés. La cuestión que se plantea es si la sociedad y la cultura contemporáneas necesitan la filosofia y si ésta es una forma contemporánea del saber o si por su esencia es algo que ya hace tiempo pertenece al pasado.

Del fin de la época cuando la filosofía había sido el líder de la vida espiritual de la sociedad ya se tenía conciencia en el siglo XIX. Solo mencionaré dos nombres Augusto Comte y Carlos Marx. Los dos proclamaron el fin de la filosofía, los dos consideraban que después de Hegel la filosofía era imposible y que 
su lugar lo venía a ocupar la ciencia. Según Marx la ciencia histórica que él denomina concepción materialista de la historia, según Comte la ciencia social o la sociología. Pero a pesar de que los dos se consideran fundadores de nuevas direcciones en la filosofía: el marxismo (el materialismo dialéctico e histórico) y el positivismo, en realidad, cada uno de ellos pretendía superar toda filosofía, o como entonces la llamaban la metafisica, para sustituirla por la ciencia.

Parecía que los dos se habían equivocado. Pues después de ellos la filosofía ha seguido existiendo, pero ya no como metafísica. En el mundo de hoy existen más filósofos que en toda la historia de la filosofía. ¿Pero en qué se ha convertido la propia filosofía? Ella se ve a sí misma o como una «sirvienta de la ciencia", que sirve a sus intereses puramente cognoscitivos o como cierta instancia que se opone a la ciencia, y cuyo significado para el hombre contemporáneo es muy problemático y dudoso. Sobre su carácter no contemporáneo o "atemporal" escribió F. Nietzsche, proclamando el nihilismo como credo, es decir, la total negación de todo aquello en lo que habían creído los filósofos, empezando por Sócrates, Platón y Aristóteles. Su libro sobre Zaratrustra lo definía como un libro para todos y para nadie. Nietzsehe consideraba que si la filosofía había sido necesaria para alguien, lo fue para los griegos, ellos fueron los que la crearon, pero incluso para estos no siempre fue una señal de salud y fuerza. Esto sólo lo fue para la filosofía presocrática y los presocráticos, mientras que después de Sócrates era un testimonio de la decadencia y descomposición del espíritu griego, su desvinculación de la vida y su muerte. La función cultural de la filosofía en las condiciones actuales, según Nietzsche, no se puede ni adivinar ni comprender, ya que ahora aquella cultura no existe.

"Sólo una cultura similar a la griega puede responder a la pregunta sobre la misión de la filosofía: sólo esta cultura puede en general justificar la filosofía pues sólo ella sabe y puede demostrar, porqué y de qué modo el filósofo no es un peregrino errante que llega de paso aquí y allám.

Si para los griegos la filosofía "era la estrella principal en el sistema solar de la cultura», en la cultura contemporánea el filósofo es tan sólo «un inesperado cometa que causa terror", que no se sabe para qué ha llegado a nuestro sistema un peregrino errante, que no se sabe donde va.

Igualmente crítico en la valoración de la filosofía contemporánea fue Spengler. Al comparar en su Decadencia de Occidente a los filósofos contemporáneos con los pensadores del pasado escribe: 
"Da vergüenza cuando de personas de tal calibre pasas la mirada a los filósofos de hoy día. ¡Que nulidad en todo lo persona!! ¡Que insignificancia en su horizonte político y práctico!... En vano miro a mi alrededor, buscando entre éstos a alguno que pueda crearse un nombre, por lo menos, por un sólo profundo y avanzado juicio en alguna cuestión decisiva de actualidad. En todas partes tropiezo con opiniones, provincianas, que se pueden escuchar de cualquiera"

y continua

"Es evidente que se ha perdido de vista el último sentido de la actividad filosófica. Esta se confunde con la prédica, la agitación, el folletín satírico, con una ciencia especial. Desde una perspectiva que se abre a vista de pájaro hemos descendido a la perspectiva de la rana. De una u orra manera la situación tropieza con el interrogante: ¿es en general posible hoy día o mañana una verdadera filosofia?

Una filosofía sistemática, que abarque todo el Universo, tal como era la filosofía del siglo XVIII, evidentemente ya no existe, también está acabada la filosofía ética. Sólo queda una posibilidad, la mutua comparación de distintos mundos culturales, utilizando para ello el método de la morfología histórica comparativa. Esta es la posición del escepticismo que niega la visión integral del mundo, no reconoce las verdades eternas u absolutas, confirma el relativismo, la relatividad histórica de cualquier juicio y opinión. El escepticismo contemporáneo niega también la posibilidad de la existencia de la filosofía como un sistema integral. Y sólo la historia de la filosofia según Spengler se acepta "como el último tema serio de la filosofia. Esto es precisamente el escepticismo".

Pudiera parecer que estos dos pensadores también se equivocaban a pesar de que por aquel mismo tiempo nacían la fenomenología, el existencialismo, la antropología filosófica, la hermeneútica filosófica y muchas otras corrientes del pensamiento filosófico contemporáneo. No obstante no podemos dejar de ver en todos ellos el desesperado intento de salvar a la filosofía, en un mundo que ya no necesitaba de ninguna filosofía. Posiblemente es esto lo que explica la abundancia en el siglo XX de corrientes filosóficas que se van alternando con velocidad calidoscópica, pero que no han alcanzado una situación dominante en la conciencia social. Ninguna de éstas se ha convertido en el líder cultural de su época, no le ha dado su nombre, no ha creado una forma de pensamiento que estuviera en concordancia con el espíritu de su tiempo. Posiblemente la que mayor éxito ha logrado es el postmodemismo, pero ¿a qué precio? La filosofía como considera el filósofo post-modernista norte americano Richard 
Rorty debe ser sustituida por la crítica literaria, comprendida como la crítica del cualquier tipo de escritura cuyo sentido sea la reproducción de todos los demás textos precedentes. La posición nihilista de Rorty y otros post-modernistas respecto a la filosofía es bien conocida, a pesar de que estos se incorporan a la tradición (en el apartado filosofía) como filósofos.

En cierto sentido la filosofía postmodernista se puede definir como anti filosofía o contra filosofía ya que, evidentemente, sólo en forma de tal auto negación puede existir en la actualidad la filosofía.

Como un ejemplo más citaré un breve párrafo de una conversación de Heidegger con los corresponsales franceses en el año 1969. Ante la observación de estos de que

"hoy día la crisis de las universidades va acompañada de una desconfianza del propio sentido de la filosofía y que para la mayoría ésta no tenía derecho a existir, había resultado inútil.

Heidegger replicó:

"Esto es, precisamente, sobre lo que yo siempre he pensado". "La filosofía es extemporal por su esencia debido a que pertenece a aquellos raros fenómenos cuyo destino consiste en que no pueden encontrar una resonancia inmediata".

La filosofía según Heidegger «es una de las raras posibilidades de una existencia autónoma creativan. El sentido de la cuestión a la que hoy día responde la filosofía, "no le preocupa a nadie», a pesar de que el planteamiento de está cuestión y el intento de encontrarle una respuesta es lo que ha creado a Occidente y a la cultura occidental.

El problema así como lo entienden muchos destacados filósofos de Occidente consiste, en la incompatibilidad de la filosofía y la contemporaneidad. Se puede, por lo tanto, no estar de acuerdo con esta opinión, pero no se puede ignorar al explicar el estado de cosas existente. La contemporaneidad en su existencia y funcionamiento, al parecer, no necesita ni de Dios, ni tampoco del hombre, por lo menos tal como su imagen se ha presentado en el espejo de la filosofia desde la antigüedad. Dios y el hombre, según han señalado los filósofos, no tienen vida en ella. En este sentido la contemporaneidad no sólo es por su espíritu 
atea, sino anti-humanista, se presenta como la negación de sus propias premisas culturales (Como se sabe, Spengler ha definido esta situación como civilización y ha visto en ella la crisis e incluso la muerte de la cultura europea). Es precisamente por esto, por lo que la religión y la filosofía pierden en ella sus precedentes posiciones. Su lugar lo pretende ocupar la ciencia la que, al liberarse del poder de la teología y la metafísica, se convierte en un instrumento del poder, en su tecnología política y económica. Al romper con la filosofía la ciencia no sirve ahora a la verdad o a la idea, como antes pensaba sobre si misma, sino al interés que en la sociedad actual adquiere el significado de una fuerza motriz de primer orden. En el mundo en que gobiernan los intereses los hombres, naturalmente, también piensan e incluso piensan racionalmente, pero sólo en los marcos de la realización de sus propios intereses. Todo lo que pasa de esto, por regla general, no les interesa. ¿Qué puede hacer el filósofo en un mundo así y a quién le es necesario? Que la filosofía es ajena a la mayoría de los hombres que viven su vida cotidiana, ya se sabía, naturalmente, con anterioridad, pero sólo en nuestro tiempo se ha empezado a hablar de su innecesidad, de que la filosofía no se necesita ni en el conocimiento, ni en la educación, ni en la cultura.

Yo no estoy aquí llamando a nadie a que se solidarice con esta opinión. Pero tampoco debemos crear la apariencia de tener claridad en la repuesta a la pregunta para qué sirve hoy la filosofía, a quién o a qué sirve en el mundo actual. Hace tiempo (en la Edad Media) la filosofía era una "sirvienta de la teología», después creyó ser "la reina de la ciencia", para convertirse después también en su "sirvienta», en la época soviética fue una "sirvienta del poder», su justificación ideológica. Pero ninguna de estas funciones es un fundamento suficiente de su derecho a existir en la situación actual: la religión, la ciencia y el poder pueden prescindir de la filosofía. ¿Acaso hoy día son muchos los científicos o los políticos que conocen la filosofía o recurren a ella para resolver sus problemas; ¿Quién de los hombres de la ciencia o del arte considera necesaria para sí la lectura de Platón, Kant, Hegel o Heidegger? Pienso que no son muchos. Ninguna persona que se considere educada y culta duda, al parecer, de la importancia y la necesidad de la filosofía, incluso se sorprende cuando esta cuestión se plantea, pero quién de ellos está en serio preocupado por el nivel de su cultura filosófica. El conocimiento de la filosofía no molesta naturalmente a nadie, pero según la opinión de muchos, no ayuda en nada, solamente proporciona la fama de erudito educado, que sabe lo que los otros no conocen.

En la práctica cultural del hombre contemporáneo la filosofía ya hace tiempo que se presenta como una colección de "sentencias y pensamientos" erudi- 
tos, que se suelen citar sin ninguna relación con el contexto en el que son pronunciados. Se ha convertido en algo así como en un "folklore cultural», emulando en esto con los refranes y proverbios populares.

En esta función la filosofía se suplanta fácilmente por todo tipo de ensayo o simple periodismo. Pero quién entre nosotros no pretende hoy día al título de filósofo. En este papel se presentan con frecuencia individuos que no sólo no tienen una formación sistemática filosófica sino algunos que ni siquiera tienen una noción de la esencia y el sentido de la actividad filosófica.

Al no encontrar demanda la filosofía se convierte en una ocupación de diletantes y marginados que ofrecen como filosofía todo lo que les viene a la cabeza. La innecesidad de la filosofía está en relación directamente proporcional con la facilidad con la que en ella florecen y se multiplican las "teorías" y las "concepciones» que no tienen raíces en ninguna tradición filosófica y no siente el peso de ninguna exigencia de la profesionalidad filosófica. Como regla sus autores suelen ser o aquellos que han fracasado en otro tipo de actividad (por ejemplo en la ciencia) y deciden tomarse la revancha en la filosofía. ¿No será acaso por esto que hoy día ésta sea percibida por muchos como cierto reposadero de personas e ideas innecesarias para todos?

La cuestión sobre qué puede y qué debe ser la filosofía en el mundo de hoy, qué función cumple en él y porqué no puede ser sustituida ahora ni por la religión, ni por la ciencia, ni por el arte y qué es lo que le permite pretender en la situación actual al status de una forma específica e independiente y, lo que es más importante, una forma de conciencia plenamente contemporánea esto es, precisamente, lo que yo quisiera que fuera discutido aquí. Se comprenderá que sobre esta cuestión yo tengo una opinión personal, pero no quisiera condicionar con ella nuestra conversación. Lo que más me preocupa es lo que piensan sobre esto los representantes de las profesiones no filosóficas, cómo comprenden y valoran el significado de la filosofía y en qué ven personalmente su valor. Posiblemente puedan decir algo que no siempre los propios filósofos ven y comprenden.

\section{Conclusiones de los ponentes}

Meshuev, V. M.

Estoy de acuerdo con aquellos que han apoyado el tema que hemos puesto en discusión y han reconocido que no es una cuestión baladí y simple, 
como hubiera podido parecer a primera vista. No puedo estar de acuerdo con aquellos que han considerado que todo está claro y no existe ningún problema. La filosofía en general empieza con la duda - ante todo al derecho de su propia existencia. Para nuestro gran filósofo Merab Mamardashvili la cuestión qué significa ser filósofo en nuestros días, se convirtió casi en el tema principal de sus meditaciones. Si, como se sabe, Hegel concluyó toda la historia del espíritu mundial con la filosofía, después de Hegel, como ya he señalado, muchos destacados pensadores llegaron a la conclusión de que la filosofía era ya imposible. Así, por ejemplo, pensaba Marx. Aquí se han referido a Marx, pero se han olvidado decir que Marx fue uno de los primeros impugnadores de la filosofía. El decía correctamente que para los griegos, que inventaron la filosofía, esta fue la forma más importante del saber. Pero después de los griegos esta empieza a perder paulatinamente su posición dominante en la cultura. En la Edad Media fue una "sirvienta de la teología». En la Epoca Moderna se convierte en una "sirvienta de la ciencia", intentando conservar para sí la función si no de saber sobre el mundo, por lo menos de teoría del conocimiento, de epistemología científica. Hoy día el significado de la filosofía como epistemología también se cuestiona (por ejemplo Richard Rorty, a pesar de que hoy la dependencia de la filosofía de la religión y la ciencia se presenta como una contraposición de la filosofía religiosa y la científica. En la época soviética, y de esto también hemos hablado, la filosofía servía al poder, rompiendo para ello no sólo con la religión, sino también con la ciencia. ¿Pero a quién sirve hoy o a quién debería servir? El lugar, el papel de la filosofía en el conocimiento, la educación y la cultura ha cambiado constantemente en el curso del tiempo y, por lo tanto, la pregunta sobre cuál es ahora su lugar y su papel y para qué es necesaria la filosofía en el mundo contemporáneo es una pregunta legítima.

En esto quiero discrepar con Viacheslav Semionovich que ve la tarea de la filosofía en el conocimiento racional y en la expresión categorial de los universales de la cultura. Con lo que posiblemente no estará de acuerdo ningún antropólogo cultural, que diría que esto lo hacemos nosotros mejor que cualquier filósofo, lo que será apoyado por el historiador y, en particular por el historiador de la cultura.

\section{Stiopin, V. S.}

Yo no he dicho que debemos estudiar estos universales, he dicho que los debemos construir. 
Meshuev V. M.

¿Constrir? Pues mejor aún. La sociología contemporánea también pretende construir la realidad. Sobre el pensamiento prospectivo hablan hoy día todos los que quieren. Pero no está claro qué ventajas tiene aquí la filosofía. Stiopin, V. S.

Bien, está claro.

Meshuev, V. M.

Según mi opinión, la filosofía a pesar de todo no construye, sino conoce, pero de modo diferente de cómo lo hace la ciencia. Es efectivamente, el conocimiento de lo que no se puede descubrir en ninguna experiencia externa, no se puede observar con la mirada habitual, incluso con los instrumentos más exactos. Se trata de la esfera de las ideas, de los significados ideales que ya Kant consideraba que no tenían objeto en la experiencia. Esto, como nos propone Viacheslav Semionovich, podemos definirlo como conocimiento, como el conocimiento del hombre europeo de su propia cultura, sus universales (en general la filosofla sólo puede ser conocimiento de su propia cultura), pero la existencia de tales universales, o ideas es, precisamente, lo que se pone en dudas por la ciencia social y la historia contemporáneas. $Y$ junto con esto se pone también en dudas todo el trabajo del filósofo. El mundo de las ideas o el mundo ideal es para los científicos algo abstracto, privado de sentido y significado científico. Nosotros vivimos en un mundo donde prevalece, no el baile de las ideas, sino el de los intereses, por cierto, en primer lugar el de los intereses materiales. En este mundo se prefiere confiar más en la ciencia que en la filosofía. Marx decía que las ideas se ven humilladas cuando se enfrentan a los intereses. Esto se convirtió para él en el fundamento de la crítica de cualquier filosofía y de su sustitución por la ciencia. En el mundo en el que los hombres prefieren guiarse no por las ideas, sino por los intereses, la filosofía con sus universales no tiene, efectivamente, nada que hacer.

No se trata de que la filosofía no sea necesaria para nadie. Pero, no existen dudas de que hoy día se encuentra en crisis ¿Qué la ha motivado? Ya en el siglo XIX los filósofos establecieron su principal enemigo. De esto hemos hablado muy poco. El nombre de este enemigo son las masas, la sociedad de masas. A 
las masas, si se entiende bien el sentido de este concepto, no les hace falta la filosofía. Las masas no se rigen por ideas, las gobiernan las élites que se rigen por sus propios intereses y utilizan para gobernar todo tipo de tecnologías: políticas, informativas y otras. Estas son las que sustituyen a la filosofía. En lugar de metodólogos preocupados por la búsqueda de la verdad, llegan los tecnólogos que buscan los medios para la realización de cualquier finalidad que se les plantee. Esto es lo que ellos definen como constructividad. Y a estos, no se porqué, también los llamamos filósofos, a pesar de que su labor se debería valorar como ingeniería social, que tiene muy poco de común con la verdadera filosofía.

¿Entonces, para quién, a pesar de todo, es necesaria la filosofía? Se puede hablar mucho sobre el significado de la filosofía para el conocimiento, la enseñanza, la educación moral, la cultura etc. (este significado es el que hoy se impugna), pero yo colocaría en primer lugar la importancia que tiene para la política. En el destino de la filosofía la política, al parecer, juega un papel decisivo. Fueron los griegos los que descubrieron que entre la filosofía y la política existía un vínculo directo. ¿Pero de qué política se trata? Pues hoy día también sirven a la política los que se definen como tecnólogos políticos. Pero sin embargo, para los griegos la filosofía era el pensamiento de aquellos que no sólo se dedicaban a la política, sino que vivían una vida política libre. El nacimiento de la filosofía está directamente vinculado al surgimiento de la antigua polis, la primera forma inicial de democracia. Según J. P. Vernant, conocido investigador del pensamiento griego amiguo

«la formación de la polis, el nacimiento de la filosofía y los estrechos vínculos entre estos dos fenómenos explican el surgimiento del pensamiento racional, cuyas fuentes se remontan a las estructuras sociales y al tipo de pensamiento de la antigua polis".

La razón griega "en todas sus virtudes y defectos... es hija de la polis».

La filosofía es el modo de pensar de los hombres libres, para los que la verdad no es lo dicho por el sabio o el profeta, sino el fin deseado de su búsqueda y sus meditaciones personales. El filósofo no es el que sabe la verdad, es su amigo que busca el camino hacia ella por medio del diálogo y el mutuo intercambio de opiniones. Los sabios y los profetas que han recibido la verdad desde el cielo, conviven con facilidad con los tiranos y déspotas y niegan a los demás el derecho a su propia opinión. Es por esto que, como regla, hayan vivido en oriente. La filosofía no es ni sabiduría, ni profecía, sino el difícil cami- 
no del conocimiento de la verdad, que exige la participación de muchos en este proceso, aquellos que tienen sus propios puntos de vista sobre las cosas, pero son capaces de comprenderse mutuamente. El diálogo entre ellos exige un lenguaje específico que debe conjugar en sí las particularidades del discurso individual con las palabras y conceptos que tienen para los participantes en el diálogo un mismo sentido y significado. La filosofía elabora, precisamente, ese lenguaje. Es el lenguaje racional de comunicación y discusión pública de los hombres libres. No es una casualidad que el florecimiento del saber filosófico coincida directamente con aquellos períodos de la historia europea, en los que tienen lugar el tránsito a la sociedad civil y a la democracia. La libertad política es imposible sin libertad intelectual y espiritual y ésta no se puede alcanzar sin su órgano principal - la filosofía.

De aquí que sea comprensible el papel de la filosofía en la formación del hombre. En su artículo La disputa de dos facultades Kant al analizar el papel de la facultad de filosofía en el sistema de la enseñanza universitaria llega a la conclusión de que ésta es una condición necesaria para la liberación de la investigación científica tanto del poder de las supersticiones y los prejuicios, como de las prescripciones e instrucciones del poder superior. Dicho en otros térininos, la educación filosófica garantiza, no el conocimiento de la verdad, esta es una tarea de la ciencia, sino la libertad de su búsqueda científica. La filosofía, si es que sirve a algo, sólo es a la causa de la libertad política e intelectual.

Pero si me dicen que la sociedad de masas contemporánea ha ampliado la esfera de esta libertad yo, posiblemente, no estaría de acuerdo. Más bien todo lo contrario: la ha reducido hasta sus límites extremos. La sociedad que a pesar de su fingido democratismo se gobierna por las élites por medio de las tecnologías más racionales (y esta es la sociedad de masas), no necesita mucho de la filosofía ¿Pero dónde buscamos en ella la libertad? ¿En las estructuras del inconsciente, en la situaciones límites, en el mundo virtual o en dónde más? La esperanza de alcanzar la libertad por medio de la razón científica y el progreso técnico que alimentaba la época de la Ilustración, acabó en ambos casos en una desilusión. ¿Qué ciencia tiene como finalidad la libertad? Todas ellas ya hace tiempo que sirven a los intereses del poder y la riqueza. El problema de la conquista de la libertad individual por el hombre ha pasado íntegramente a la filosofía, la que mantiene hacia la sociedad y la ciencia contemporancas una posicion muy crítica. Posiblemente nadie se atrevería a afirmar que este problema ya está en general resuelto en la sociedad actual, o que algún día será 
resuelto por completo. Al resolverlo nos convertimos en filósofos. Estoy de acuerdo con Guseinov ${ }^{38}$ que aquí me ha criticado, de que la toma de conciencia de este problema es ya de por sí un gran progreso. Pero para los que no existe este problema la filosofía pierde todo sentido.

Quisiera ser bien entendido: la filosofía de por sí no hace a nadie libre, pero hace posible comprender el sentido de la libertad, crea para ésta su lenguaje, aclara los que se interpone en su camino. La libertad en su interpretación filosófica es una condición de la vida humana que sólo puede acercarla a la verdad, al bien y la belleza, es decir, hace posible la existencia de la ciencia, la moral y el arte. Sin libertad estos se convierten en lo que hoy día podemos observar: La ciencia no es la búsqueda de la verdad, sino un medio instrumental para la realización de cualquier interés, la moral es la justificación de este último y el arte la tolerancia de cualquier gusto. Lamentablemente esta situación a muchos les parece normal. $Y$ del mismo modo que el creyente nunca traiciona a su Dios, lo mismo el filósofo, fiel a su destino, nunca se colocará en las filas de aquellos que han aceptado esta normalidad. Ahora puedo dar la palabra al otro ponente.

Stiopin, V. S.

Pero teniendo en cuenta lo que has dicho sobre la libertad ¡Puedes no darme la palabra!

\section{Meshuev, V. M}

Yo he hablado de la libertad y usted confirmará lo que he dicho, pues si yo no se la hubiera dado Usted la habría tomado por su cuenta.

\section{Stiopin, V. S.}

¡Naturalmente, ya que somos libres!

38 Guseinov, A. A: Académico, Vicedirector del Instituto de Filosofía de la A.C.R. 
Stiopin, V. S.

Mucho de lo que hemos hablado aquí se puede precisar y, entonces, pudiera ser que algunos de los problemas que pueden parecer muy discutibles dejarían simplemente de serlo. Digamos que es muy importante tener presente que los propios tipos de filosofar cambian históricamente y que sólo la filosofía clásica ha pretendido crear sistemas acabados y estables. Por cierto que en esta pretensión existían determinados aspectos racionales. El filósofo que construía un sistema mostraba que existía una profunda relación entre la comprensión de la causalidad, el espacio y el tiempo, la libertad, la justicia y la conducta moral de los hombres. El sistema integral vinculaba estos sentidos categoriales entre sí. Todo el pensamiento filosófico clásico en general, toda la conciencia clásica y no sólo en la filosofía, sino en la ciencia representaba un tipo específico de conciencia.

Habermas ha mostrado muy bien, a mi modo de ver, que el paradigma filosófico clásico esta basado en la siguiente contraposición: existen el ser y la razón y entre estos no existen mediadores. El ser es trasparente para la razón, luego se puede decir que la razón es primaria y el ser secundario, pero puede ser al revés. Tanto el materialismo como el idealismo en esta versión se presentan como variantes del enfoque clásico. Pero la (filosofía) no clásica descubre que entre la razón y el ser existe un mediador. Este es la actividad y el lenguaje, entendidos en sentido amplio, como lenguajes de la cultura. $Y$ es entonces cuando ya no se puede considerar a la razón cognoscente como algo sin premisas, soberano, que tiene su fundamento en sí mismo. Esta debe tratarse como sumergida en un detenninado medio social de actividad cultural. Es aquí, cuando surge el problema de si es posible construir el último sistema filosófico absolutamente veraz. Naturalmente que no. Cada uno de estos sistemas está condicionado por la cultura de su época y, debido a esto, es limitado. Toda la crítica que se ha citado aquí de Marx y Comte estaba dirigida contra la tradición clásica y, por lo tanto, el marxismo y el positivismo se pueden considerar, en cierta medida, como variantes o pruebas de tipos no clásicos de filosofar.

Pero entonces surge el problema: si la filosofía no puede pretender descubrir las últimas y definitivas verdades del ser ¿ Significa acaso esto que la filosofía ha muerto? No. Simplemente ha cambiado el modo de filosofar. Y todo el desarrollo ulterior de la filosofía en el siglo XX se orienta hacia este tipo no clásico de filosofía. Pero esto también es una nueva comprensión del objeto de la filosofía. Es necesario definirla de tal modo que la clásica y la no clásica encuentren 
su lugar en esta definición generalizadora. A mi modo de ver esta tarea se resuelve si definimos la filosofía como una reflexión sobre los universales de la concepción del mundo de la cultura. Vadim Mijaílovich subrayaba, que lo más importante en la comprensión de la filosofía es la libertad. Pero la libertad es uno de los universales más importantes de la cultura y su comprensión históricamente cambia. Se trata de uno de los problemas filosóficos más importantes. Debido a que los fundamentos de la cultura son históricamente cambiantes esto significa que los sentidos de los universales de la concepción del mundo también cambian y esto implica que el filósofo no debe pretender alcanzar definitivamente la verdad sobre estos sentidos, sino que debe tener una actitud crítica hacia cada una de las etapas de su asimilación filosófica. Estoy de acuerdo con Rabinovich ${ }^{39}$ de que todo empieza por el asombro. ¿¿De qué tipo de asombro? Del más simple: los hombres están acostumbrados a considerar que la libertad es esto, mientras que el filósofo propone otro punto de vista e incluye en éste nuevos sentidos. El filósofo tiene una actitud crítica hacia las opiniones en boga en la cultura sobre la libertad, analizando e inventando una nueva comprensión. Esta es la misión de la filosofía, la causa del filósofo. Al renunciar a construir un último y decisivo sistema el filósofo no clásico no renuncia en general al pensamiento sistémico, al establecimiento de los vínculos entre las categorías. Él como antes observa de qué modo el cambio de las representaciones sobre la libertad modifica la comprensión de la personalidad, el derecho, la justicia, la actividad, la relación con la naturaleza, etc. Pero a diferencia del filósofo clásico él acepta la posibilidad de la aparición de nuevos sentidos de los universales, aun no analizados y descubiertos por la filosofía. Por ello en el enfoque no clásico la filosofía no se termina en ninguna de las etapas, mientras continúe el desarrollo de la sociedad y la historia.

Ahora otra cuestión: ¿Acaso puede ser filósofo solamente aquel que ha terminado la facultad de filosofia o trabaja en un instituto de investigación, es decir, se dedica profesionalmente en este tipo de trabajo? Pues claro que no. $Y$ cuando yo digo que Tolstoy y Dostoevsky eran filósofos con ideas filosóficas originales, estoy hablando no de aquello a lo que profesionalmente estos se dedicaban, sino sobre la función de la conciencia de lo que ocurre cuando ésta se convierte en filosófica.

39 Rabinivich, V. L. Participante en la discusión Doctor en filosofía, investigador científico del Instituto de Filososfia de la A.C.R. 
La filosofía, cuando se ha convertido en no clásica, empieza a orientarse hacia el análisis de las diferentes esferas de la cultura, de los estados de la cultura, para comprender de este modo, cómo cambian históricamente los sentidos vitales de los universales de la cultura, cómo se elaboran y cómo se pueden descubrir y representar como sistemas categoriales filosóficos, con los que se puede trabajar. Y la filosofía siempre apela una y otra vez a este material. Pero la cultura es un material ilimitado Pero entonces iqué debe hacer la filosofía en los marcos del enfoque no clásico? El filósofo renuncia a la construcción del último sistema absoluto. Es ahora cuando él se convierte en un filósofo de la ciencia, de la cultura y estudia una determinada esfera de la realidad - la estética y la ética. Al estudiar cierta esfera de la cultura y trabajando en ella, compara más tarde los sentidos descubiertos de la concepción del mundo. ¿’Pero acaso esto significa que la metafisica como la última y superior esfera de la filosofía ha desaparecido? No. Pero esta metafísica ya no se presenta como cierto esquema final, sino que se distribuye entre todas estas investigaciones que se llevan a cabo por los filósofos de la ciencia, los filósofos sociales, los filósofos de la política.

La filosofía tiene sus propios problemas eternos. Kant destacó cuatro de estos: ¿QQué puedo saber? ¿Qué debo hacer? ¿Qué puedo esperar? Y ¿Qué es el hombre? Estos problemas son eternos y a ellos responde cada época y son puntualizados en las siguientes. La función de la filosofía precisamente consiste en la continuación de este movimiento. Es ella la que propone a la cultura las nuevas variante de otros sentidos de la concepción del mundo distintos de los hoy día dominantes, que regulan la actividad vital humana.

Cuando me dicen que ahora no es la filosofía, sino la tecnología la que condiciona la conciencia, yo respondo, que como filósofo no puedo limitarme a la constatación de este hecho. Me veo obligado a plantear la pregunta: ¿̨Porqué esto es así? Y ¿Qué tipo de conciencia surge en este caso? ¿Qué valores la sancionan? Parece evidente, que esta situación ha surgido porque se ha reconocido el valor intrínseco de las nuevas tecnologías y está vinculado con un tipo específico de relación hacia las innovaciones. Estos son, precisamente, los ídolos de la cultura tecnogénica: inventa la tecnología, introdúcela, y lo que resulte de esto luego se verá. La nueva tecnología, que aporta un efecto pragmático inmediato, es de por sí un valor. Así está construida esta civilización. Pero si yo digo que esta no es el fin de la historia, entonces surge otra pregunta: ¿ ¿Acaso las innovaciones siempre han sido un valor? Al tratar este tema apelo a la experiencia de las sociedades tradicionalistas, en las que las innovaciones, entre ellas las tecno- 
lógicas, nunca tuvieron de por sí un valor intrínseco. Por lo contrario. En ellas, según la alegoría china, se consideraba, que vivir en una época de cambios era el peor destino para el hombre. Las innovaciones en las culturas tradicionalistas se valoran de otro modo, estas no deben romper la tradición. Lo nuevo se puede introducir, pero incorporándolo a la tradición, adaptándolo a ella. Se necesita el análisis filosófico de qué consecuencias surgen para el hombre ante la aparición y divulgación de nuevas y nuevas tecnologías, entre éstas las tecnologías contemporáneas de dirección de la sociedad, que presuponen la manipulación de la conciencia. La filosofía no inventa simplemente ciertos nuevos sentidos y se los ofrece a la cultura, sino que intenta mostrar que estos sentidos no niegan todos los precedentes, que pueden ser adaptados a la cambiante tradición cultural ¿Cómo? La filosofía une aquello que hoy día se inventa con aquello que había sido inventado ayer y antes de ayer, luego observa cómo estos sentidos pueden funcionar en las diferentes esferas de la cultura. Es un trabajo inmenso. Pero ningún antropólogo lo hace. Retornando al tema de los eternos problemas filosóficos, queremos señalar cómo los planteaba Kant. ¿Por dónde empezaba? Preguntando ¿Qué puedo saber? Es decir por la racionalidad, por el saber. De aquí se deducían las orientaciones de la acción práctica y las valorativas ¿Qué puedo esperar? Como resultado el esperaba obtener un saber sobre el hombre.

La filosofía no clásica plantea la cuestión y razona de otra manera. Empieza por la pregunta ¿Qué es el hombre? Por el análisis previo del propio mundo vital humano, esto se debe a que el conocimiento está sumergido en él y por él determinado. Y sólo más tarde el análisis de lo que es el conocimiento, la actividad práctica, los valores y de nuevo, pero ya en forma enriquecida y concretizada, retoma al problema ¿qué es el hombre?

Meshuev, V. M.

Y así Foucault llegó a la conclusión de que el hombre no existe.

\section{Stiopin, V. S.}

Esta es otra cuestión. El filósofo tiene también derecho a decir esto, porque él piensa en el hombre no sólo como en el hombre de su época. Él lo vincula al ideal del hombre. Incluso puede problematizar este ideal. Por ejemplo, Marcuse decía que la civilización contemporánea había creado un hombre uni- 
dimensional y Marx escribía sobre los crecientes procesos de enajenación y sobre el fenómeno del «hombre parcial».

Meshuev, V. M.

Marx no consideraba que con la ayuda de la filosofía se podía superar la parcialidad del hombre .

Stiopin, V. S.

Marx no consideraba muchas cosas, pero yo no estoy hablando de eso. Lo que yo digo es que el problema del hombre es un problema eterno en la filosofía. Por eso cuando surgen concepciones del hombre unidimensional, parcial, el problema de la enajenación, el problema de la destrucción de la personalidad -todo esto son aquellos nuevos aspectos del problema del hombre que hoy día son de actualidad debido al desarrollo de la civilización tecnogénica contemporánea. $\mathrm{Y}$ es a estos problemas a los que debemos dar una respuesta.

Y ahora lo último. Teniendo presente que la filosofía inventa ideas que no se sabe cómo serán recibidas en el futuro ("no nos es dado adivinar que repercusión tendrán nuestras palabras"), yo no puedo establecer, quién de mis colegas, los filósofos que me rodean, pudieran en el futuro ser valorados como destacados pensadores y quienes no. Salam Kerimovich Guseinov ha citado ejemplos, entre ellos el de un premio Nobel de filosofia ${ }^{40}$ mostrando que la actitud de los contemporáneos ante los filósofos no prestó su atención en aquellos que más tarde fueron altamente valorados, sobrevalorando a algunos de los que hoy día ya nos hemos olvidado. Por esto yo, a diferencia de Spengler, tengo otra actitud hacia mis colegas. Veo en ellos, no unos individuos lamentables e incapaces, sino responsables pensadores.

Esto, naturalmente, no significa que en la filosofía de hoy no existen fenómenos de crisis. La filosofía no ha elaborado en la medida requerida las nuevas 40 Se refería al filósofo alemán Rudolf EUCKEN quien en 1908 recibió el premio Nobel de
literatura. ${ }^{40}$ Se refería al filósofo alemán Rudolf EUCKEN quien en 1908 recibió el premio Nobel de
literatura. 
ideas, apoyándose en las cuales hubiera sido posible encontrar una salida de las crisis actuales de la civilización. Hoy día los cambios sociales transcurren a un ritmo tal que la conciencia no los puede con frecuencia asimilar a tiempo. Los digiere post factum. Pero de aquí no se deduce que la filosofía está agonizando, que no es necesaria. Al contrario, se deduce la necesidad de activar el pensamiento filosófico, la búsqueda de nuevos procedimientos y enfoques para la realización práctica de las ideas elaboradas por la filosofía.

\section{Tolstij, V. I.}

Colegas, una vez, aún en los tiempos soviéticos, participé en la reunión del activo de la fábrica de automóviles "ZIL" Participaban unas 1.200 personas y una de ellas me hizo la siguiente pregunta: como filósofo usted nos ha planteado aquí correctamente todas las cuestiones, pero no nos ha ofrecido ninguna respuesta y no nos ha dicho qué es lo que tenemos que hacer. Mi respuesta fue: como usted sabe entre nosotros se ha establecido que si el filósofo plantea correctamente una cuestión, ya puede pasar directamente por la taquilla. Hubo risas e incluso aplausos. Considero que hoy nuestros ponentes han planteado todas las cuestiones en forma interesante y correcta. Lamentablemente no tenemos taquilla. 